\title{
Mammalian Auditory Cortex Structure as the Basis of Cortical Sound Processing
}

\author{
Gleb Khorunzhii, Marina Egorova* \\ I.M. Sechenov Institute of Evolutionary Physiology and Biochemistry, RAS, Saint-Petersburg, Russia \\ Email: *ema6913@yandex.ru
}

How to cite this paper: Khorunzhii, G. and Egorova, M. (2018) Mammalian Auditory Cortex Structure as the Basis of Cortical Sound Processing. Journal of Behavioral and Brain Science, 8, 641-673.

https://doi.org/10.4236/jbbs.2018.812040

Received: November 5, 2018

Accepted: December 7, 2018

Published: December 10, 2018

Copyright $\odot 2018$ by authors and Scientific Research Publishing Inc. This work is licensed under the Creative Commons Attribution International License (CC BY 4.0).

http://creativecommons.org/licenses/by/4.0/

\section{(c) (i) Open Access}

\begin{abstract}
The basic morphological aspects of auditory cortex organization in different orders of eutherian mammals are considered in the present review. The modern data describing a partitioning of mammalian auditory cortex into subfields are presented. A detailed observation of the structural organization of primary auditory cortex is given, as well as a review of recent morphological data about secondary auditory areas. Another section describes the system of auditory cortical projections. The data are considered from the perspective of possible homologies existing between the auditory cortices in different mammalian species.
\end{abstract}

\section{Keywords}

Auditory Cortex, Primary and Secondary Auditory Cortical Fields, Auditory Cortical Projections

\section{Preface}

At present, there are extensive data about the morphological structure of the mammalian auditory cortex obtained in numerous studies with different experimental approaches and methods [1]-[20]. The set of experimental objects used in this research is large. Despite this, information about partitioning of the auditory cortex into separate sub-regions and about its connectivity among different mammalian orders has not been summarized in detail. Our review aims to systematically present the available data about the structural organization and connectivity of the auditory cortex in eutherian mammals.

The first part of this review contains a detailed description of the auditory fields' disposition in the temporal lobe of the neocortex among a significant number of mammalian species. The common scheme of the auditory cortex spatial organization initially proposed by Woolsey and Walzl (1942) for cats [21] 
and later applied to other animals [2]-[20] [22] [23] [24] was used as a framework for the present review. For each mammalian order, we separately describe primary and secondary auditory fields as well as the auditory parabelt, their disposition within the auditory cortex, tonotopic organization and the relative size of these areas.

The second chapter presents data on the connectivity patterns of the auditory cortex. First, we focused on the projection system of the cat auditory cortex, which is the most studied among all eutherians. Second, we observed connections in the auditory cortex regarding their source contributions to the total volume of the auditory cortical projections.

In both chapters, we focused on basic aspects of auditory cortical structure in the mammalian phylogenetic tree rather than on their functional organization. The data systematised here provide a necessary base for an in-depth analysis of acoustic information processing in the auditory cortex and for an integrative scheme of sound encoding by the brain's auditory centres.

\section{Introduction}

The neocortical temporal lobe, which receives large inputs from the thalamic medial geniculate body (MGB) and contains neurons responding to acoustic stimulation, is generally classified as the auditory cortex [25]. A number of anatomical, physiological and behavioural studies, some of which were performed over 100 years ago, repeatedly showed that the auditory cortex is a complex structure consisting of several fields [26] [27] [28] [29]. These fields can be distinguished on the basis of their cytoarchitectonics, connectivity, functional mapping and neuronal processing.

Systematic studies of the auditory cortex's functional organization began in 1942 with a study by Woolsey and Walzl in which the authors mapped a distribution of the slow-wave evoked potentials in the ectosylvian region of the cat cerebral cortex under local electrical stimulation of the auditory nerve fibres in a cochlear labyrinth [6]. The topography of frequency representation (i.e., its high-ordered spatial distribution within the auditory cortex) was shown by Woolsey and Walzl for the first time. Based on the results of evoked potential recordings in the cat auditory cortex [21] [22] [23], its cytoarchitectonic analysis [30] and MGB retrograde degenerations evoked by local lesions of auditory cortical areas [31] [32], Woolsey suggested a scheme of the cat auditory cortex's organization (Figure 1).

In accordance with this scheme, the auditory cortical area was divided into a primary auditory field (A1) and several other fields surrounding A1. Woolsey adapted the model of cat auditory cortex to other mammals, especially to primates [33] [34] [35] [36].

Currently, subdividing the auditory cortex into separate fields is a foundation for the description of its structural organization. As a rule, the auditory cortex contains a primary auditory field (core) that is surrounded by the auditory belt and parabelt. Primary auditory fields belong to granular neocortex with 


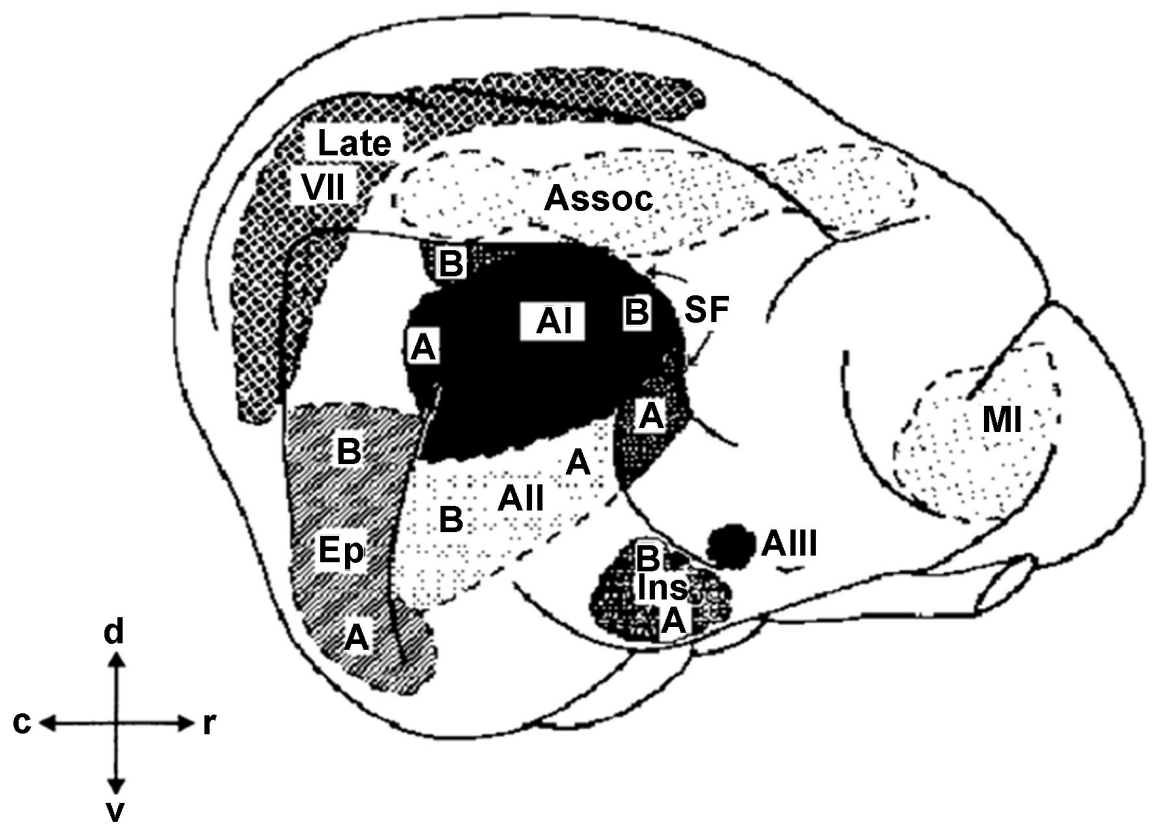

Figure 1. Representation of the cat auditory cortical area, suggested by Woolsey [22]. AI-primary auditory field (black filling). Dashed and dotted lines indicate approximate borders of areas. Ep-posterior ectosylvian gyrus, AII-secondary auditory field, SF-suprasylvian peripheral area, Ins-insular area, AIII-temporal auditory field, Assoc-associative cortex. MI-precentral motor cortical area, Late VII-visual cortex. In tonotopic auditory fields the direction of frequency increase is indicated (from A to B). $\mathrm{d}$-dorsal direction, $\mathrm{v}$ - ventral direction, $\mathrm{r}$-rostral direction, $\mathrm{c}$-caudal direction. Modified from: [49].

developed cortical layers II and IV receiving a large pool of both specific and non-specific thalamocortical projections. Primary auditory fields have a coniocortical cellular structure, receive direct inputs from MGB and differ from other auditory fields by a number of biochemical properties. Coniocortical cells in the neocortex usually demonstrate a small percentage of large pyramidal neurons and are predominated by densely distributed small stellate cells. The basic source of the primary auditory cortex afferents is a main lemniscal auditory pathway-the system of ascending projections rising from the auditory brainstem and reaching MGB as part of the lateral lemniscus fibres. The secondary auditory belt is usually located on the periphery of the primary auditory core. Due to its cytoarchitectonics, the auditory belt is defined as agranular neocortex with the thick cortical layer III (pyramidal) where there is a high spatial density of cells, including large pyramidal neurons. The extensive development of cortical layer III is provided by many associative and commissural fibres, located within this layer. Secondary auditory fields receive a large set of afferents from different parts of MGB and cortical primary auditory fields.

The associative region of the temporal cortex is usually classified as the auditory parabelt. This part of auditory cortex receives inputs from non-lemniscal sources [37] [38] [39]. This so-called "diffuse" or "additional to the lemniscal" auditory system has significant convergent inputs from sensory systems of other 
modalities but demonstrates a strong response to acoustic stimuli [25]. It seems that the diffuse auditory system doesn't have direct connections with primary auditory areas but receives rich afferentation from the secondary auditory cortex, medial pulvinar, thalamic suprageniculate nucleus and nucleus limitans. Weak afferent inputs to the auditory parabelt rising from dorsal and medial parts of MGB have also been described [40]. Currently, the non-lemniscal auditory pathway is known as a part of a higher order stage of processing, constituting a secondary system capable of processing more complex aspects of auditory scene analysis [1]. On a cortical level, this integrative system of sound processing is closely associated with the auditory belt and parabelt [1] [37] [38].

Thus, as the main integrative centre of the mammalian auditory system, auditory cortex provides the basement for hierarchical (serial) cortical sound processing [15] [16], being involved in the different aspects of acoustic information analysis, which become more complex and more integrative from the primary auditory cortex up to auditory parabelt.

\section{Subdividing the Auditory Cortex into Fields in Different Mammalian Orders}

It was shown in numerous studies of the auditory cortex in eutherian mammals over the last 50 years that all of the studied animals had auditory cortices consisting of several separate auditory fields [2]-[20] [22] [23] [24]. The number of fields increases with the evolutionary development from 2 in insectivores to 4 - 7 in rodents and from 6 to more than 8 in carnivores and primates, respectively [41]. This is related to the increase in the relative size of cerebral cortex in different mammalian orders. The only exception is marsupial mammals, for which only the primary auditory field has been shown [42] [43].

\subsection{Auditory Cortical Fields in Insectivores}

Among different insectivore species, the auditory cortex has been studied in hedgehogs and shrews. The auditory cortex of the long-eared hedgehog ( Hemiechinus auritus) is located in a lateral part of the medial temporal lobe, medial to sulcus olfactorius [44]. The primary auditory cortex boundaries in this animal were defined by electrophysiological recordings of single neurons and by labelling with horse-radish peroxidase of MGB projections to the auditory cortex. Recordings of the neuronal responses evoked by tonal stimuli revealed the spatial distribution of frequency representations within the primary auditory cortex, with high frequencies located caudally and low frequencies located rostrally. Another auditory area was found caudal to the primary auditory field. Neurons in this area responded to sounds, but ordered distribution of frequencies was not shown [44].

In the east-African hedgehog (Atelerix albiventris), the primary auditory field (A1) was defined in a caudolateral region of neocortex [45] [46]. Sound-evoked responses were also recorded in the secondary somatosensory (S2) and parie- 
tal-ventral (PV) cortical areas bordering the auditory cortex of this animal [45] [46].

In the northern short-tailed shrew (Blarina brevicauda), the auditory cortex was found in an extremely caudolateral part of the neocortex. The properties of single cells in the shrew auditory cortex remain poorly studied [46].

\subsection{The Auditory Cortical Fields in Carnivores}

Woolsey defined four tonotopic (or cochleotopic) fields in the cat auditory cortex containing a representation of the whole frequency range of a cat's hearing: the primary auditory field (A1), secondary auditory field (A2), posterior ectosylvian field (EP) and suprasylvian peripheral field (SF) (Figure 1) [21] [22] [23]. Woolsey also included in the cat auditory cortex a temporal auditory field (T) similar to the field A3 in the dog's auditory cortex [7], insular region (Ins) [47] and associative cortex, which were studied in detail by Thompson and Sindberg (1960) [48] (Figure 1). Auditory evoked potentials were also recorded in the precentral motor cortex (Figure 1) and visual cortex [25]. Further data from electrophysiological mapping of the cat auditory cortex [9] [49] [50] [51] slightly modified the original Woolsey's scheme, bringing it to the present state (Figure 2). Thus, the A1 location defined by Woolsey and Walzl did not change dramatically. Another full frequency representation was revealed rostrally to the A1 in the region of the anterior ectosylvian gyrus, which was first mapped by Woolsey as part of the suprasylvian peripheral region. This area was mapped in more detail by Knight (1977) [52] as well as by Reale and Imig (1980) [9], who named it the anterior auditory field (AAF) (Figure 2). Aside from these two primary fields, two other tonotopically organized auditory areas were related with the core regions of the cat auditory cortex, the posterior $(\mathrm{P})$ and ventroposterior (VP) fields [9] [49]. The auditory belt surrounding the primary auditory cortex was subdivided into secondary (A2), ventral (Ve), temporal (Te) and insular (Ins) fields, and the posterior ectosylvian region was additionally divided into dorsal (EPD), medium (EPM) and ventral (EPV) parts of posterior ectosylvian gyrus [50] [51]. It is noteworthy that, in a study performed by Reale and Imig in 1980 [9], the posterior ectosylvian area was identified as a dorsal auditory field. The dorsal region of this field corresponding to EPD was defined as a dorsal auditory zone (DZ) based on the analysis of functional properties of its neurons [17] [53].

Around the same time that Woolsey and colleagues studied the cat auditory cortex, a similar cortical area in dogs was mapped by Tunturi [7]. By recording auditory evoked potentials, he noticed responses to sounds in four cortical areas. These areas were named the posterior ectosylvian field (PES), medial ectosylvian field (MES), anterior ectosylvian field (AES) and tertiary auditory field (A3) [7]. A full tonotopic map of frequencies occurred in the MES cortical area. Evidence for an ordered frequency representation was also obtained in AES located rostrally to MES similar to the relative disposition between AAF and A1 in cats. PES 


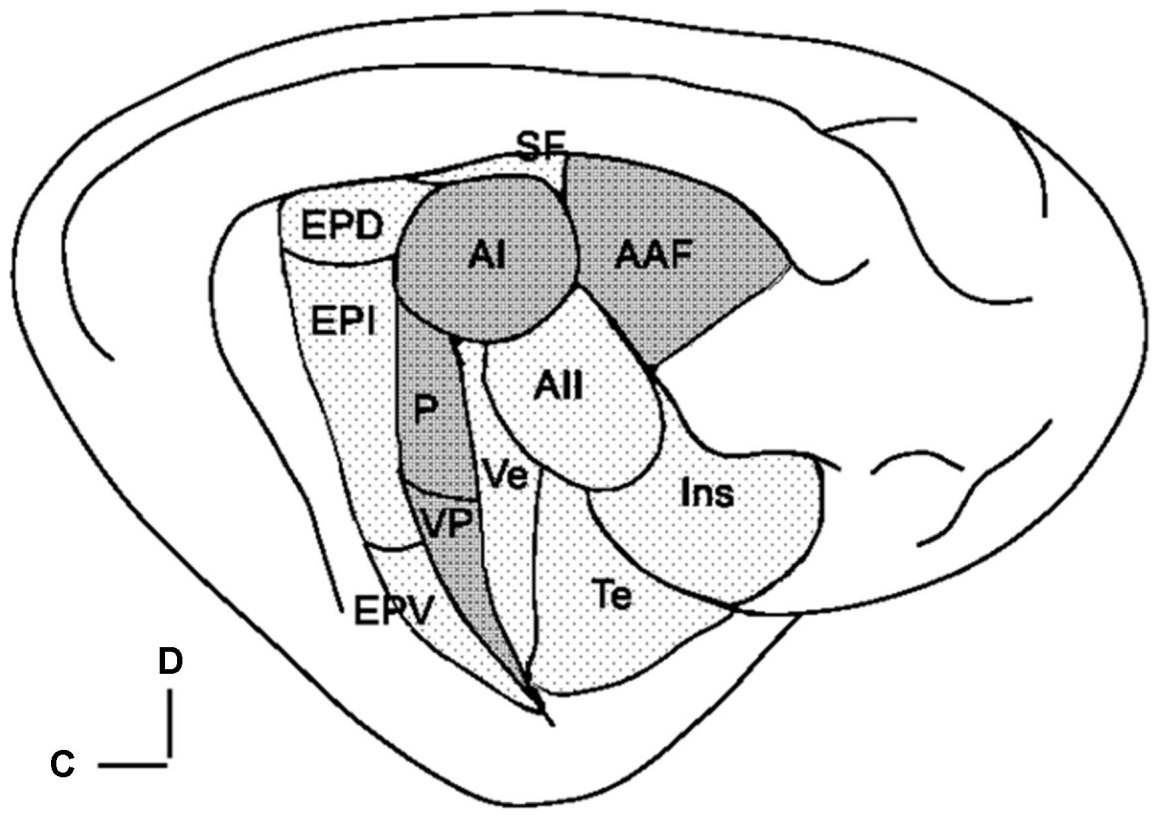

Figure 2. Auditory cortical fields in the cat [50]. Tonotopically organized fields, receiving inputs from the ventral MGB, are marked with grey filling. Non-tonotopically organized fields, receiving inputs from other MGB subregions, are marked by light grey. AI-primary auditory field; AAF — anterior auditory field; AII — secondary auditory field; EPD—posterior ectosylvian gyrus, dorsal part; EPI-posterior ectosylvian gyrus, intermediate part; EPV-posterior ectosylvian gyrus, ventral part; Ins-insular cortex; Te-temporal cortex; $\mathrm{P}$ - posterior auditory field; $\mathrm{Ve}$ - ventral auditory field; VP-ventroposterior auditory field; $\mathrm{SF}$-suprasylvian fringe area; $\mathrm{D}$-dorsal direction, $\mathrm{C}$-caudal direction.

in dogs occupies the same cortical area as EP in the cat auditory cortex, and the A3 field in the dog cortex corresponds to the temporal auditory field (Te) in cats.

In the ferret auditory cortex studied by autoradiography [54] and neuronal activity recordings under sound stimulation [18] [55] [56] [57] [58], three distinct areas were revealed near the medial ectosylvian gyrus. The first of them is the medial ectosylvian gyrus (MEG), which is identified as a primary auditory cortex. Within this area, two tonotopically organized auditory fields were described, A1 and AAF [18] [58]. The second area is located in the anterior ectosylvian gyrus and includes anterior ventral (AVF) and anterior dorsal (ADF) auditory fields [18] [58]. The last large auditory area was found in the posterior ectosylvian gyrus, which includes posterior pseudosylvian field (PPF) and posterior suprasylvian field (PSF) [18] [57] [58]. PPF and PSF are tonotopically organized. In AVF and ADF, the tonotopy was not shown [18] [58].

\subsection{Auditory Cortical Fields in Rodents}

The auditory cortex in rodents has long attracted much attention from neurobiologists. Considerable data about its anatomical structure, its subdivision into separate fields, frequency organization and cellular physiology have been obtained. To date, the auditory cortex has been studied in rats [4] [5] [59]-[65], mice [6] [11] [13] [16] [66]-[74], gerbils [12] [75] [76], guinea pigs [10] [14] [19] 
[77] [78] [79] [80] [81], squirrels [82] [83] [84] and chinchillas [85] [86] [87]. In all studied rodent species, primary and secondary auditory cortical fields were found. The number of auditory cortical fields varies among different rodent species.

In the house mouse auditory cortex (Figure 3(a) and Figure 3(b)), three primary auditory fields (primary auditory field (A1), anterior auditory field (AAF), ultrasound field (UF)) and two secondary auditory fields (dorsoposterior field (DP) and secondary auditory field (A2)) were defined [12] [70]. Two core fields are tonotopically organized, A1 and AAF (located rostrally to A1). UF is located dorsorostrally to A1. The dorsocaudal border of A1 is adjacent to the DP field. The ventral border of A1 flanks A2 (Figure 3(b)). Recently, this scheme was modified by Tsukano and colleagues (Figure 3(c)) [88] [89] [90]. Using the optical imagination method based on flavoprotein fluorescence imaging (FFI), the authors identified six distinct fields in the mouse auditory cortex. Four of them are tonotopically organized: A1, A2, AAF and dorsomedial field (DM), while two fields (DP and dorsoanterior field (DA)) have no tonotopy (Figure 3(c)). A1, AAF and A2 include distinct ultrasonic frequency bands with CFs over 40 $\mathrm{kHz}$. DM and DA also include neurons responding to the ultrasound stimuli. It was assumed that the region first annotated as the UF was a mixture of the DA and high frequency bands of the DM [90] (Figure 3(b) and Figure 3(c)).

The rat auditory cortex contains at least four primary auditory fields: A1 and AAF, which are typical for most rodents, and also suprarhinal auditory field (SRAF) and posterior auditory field (PAF) [63] [91] [92] [93]. In addition, Profant and colleagues referred to an area in the rat primary auditory cortex as "unspecific auditory region" (UR) [93]. The primary auditory cortex is surrounded by a number of secondary fields localized in the temporal cortical areas Te2 and Te3 [62] [93] [94].

In the auditory cortex of the Mongolian gerbil, seven fields were identified [12] [95] [96] [97]. Two of them demonstrated strong tonotopy and, similar to the mouse auditory cortex, were named the primary auditory field (A1) and anterior auditory field (AAF), with AAF located more rostrally. Primary auditory fields were surrounded by several secondary areas named the ventral $(\mathrm{V})$, ventroposterior (VP), dorsoposterior (DP), anterior-ventral (AV) and dorsal (D) auditory fields.

In the auditory cortex of the guinea pig, at least two tonotopically organized primary fields were identified, the anterior auditory field (A) and dorsocaudal field (DC) [10] [77] [78]. Mutual arrangement of these fields corresponds to the disposition of $\mathrm{A} 1$ and $\mathrm{AAF}$ in murine rodents. Aside from these two primary fields, a tonotopically organized small core auditory field (S) was defined by Redies and colleagues [10] as positioned rostrally to A1. In a cortical region surrounding the guinea pig primary auditory cortex, four secondary fields were described: secondary dorsocaudal (DCB), secondary ventrocaudal (VCB), secondary dorsal-rostral (DRB) and secondary ventral-rostral (VRB) fields [14] [78]. Furthermore, based on differences in neuronal response latencies, Horikawa and 
(a)
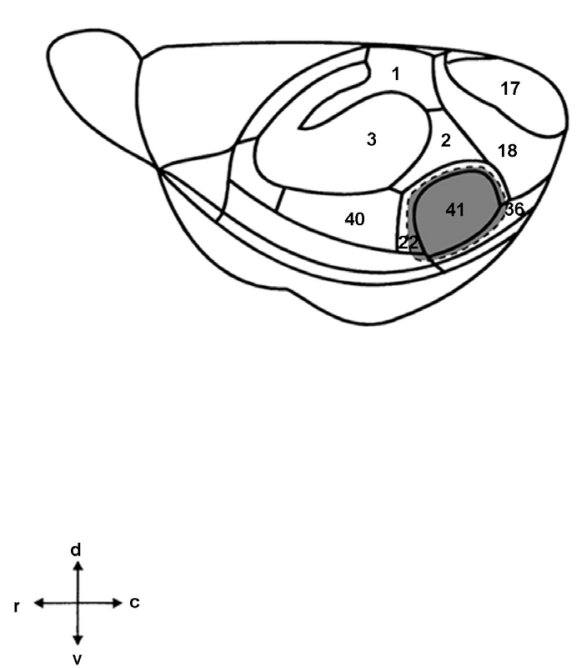

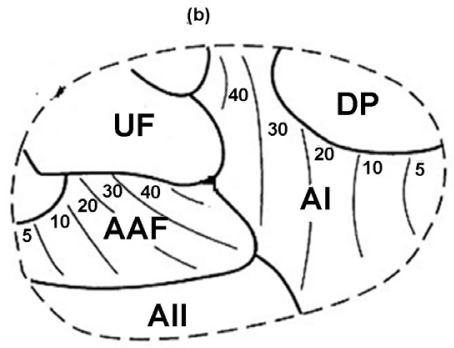

(c)

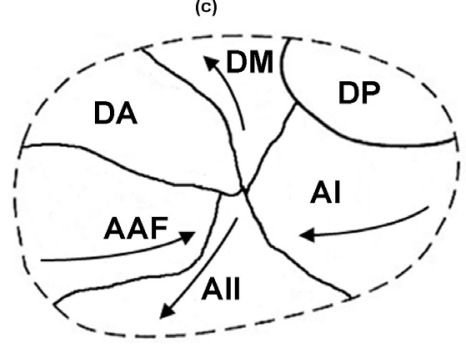

Figure 3. Auditory cortical fields in the mouse. (a): lateral view of the left-side cortex with areas shown that are delimitated on the basis of cytoarchitectonic criteria [13]. Auditory cortex (field 41) is marked with grey filling. (b): original map of spatial organization of primary and secondary auditory cortical fields in the house mouse, obtained by Stiebler et al. [13]. (c): the scheme of the mouse auditory cortex, suggested by Tsukano et al. Modified from: [90]. AI-primary auditory field, AAF—anterior auditory field, UF-ultrasound field, AII-secondary auditory field, DP—-dorsoposterior auditory field, DM-dorsomedial auditory field, DA-dorsoanterior auditory field. On (b) the regular tonotopy in AI and AAF is shown. On (c) arrows indicate the direction of frequencies increase in AI, AAF, $\mathrm{DM}$ and AII. $\mathrm{d}$-dorsal direction, $\mathrm{v}$ - ventral direction, $\mathrm{r}$-rostral direction, $\mathrm{c}$-caudal direction.

colleagues proposed to subdivide the secondary auditory cortex of guinea pigs into eight separate fields [80].

In the grey squirrel, a region of the temporal cortex responding to acoustic stimuli was separated in a similar manner to other rodents into subregions on the basis of their physiological and cytoarchitectonic properties [82] [83] [84]. One of these subregions, containing the full map of frequency representations, was considered by Merzenich and colleagues to be homologous to the A1 field of the cat and primates [85]. In the rostral field (R) located rostrally to A1, tonotopy was also shown [86]. Among secondary auditory fields in the grey squirrel, up to seven separate belt fields are identified [87].

In the auditory cortical area of the chinchilla, three tonotopically organized fields are described: A1, AAF (located rostrally to A1) and the secondary field (A2) located ventrally to the core areas [85] [86] [87]. Organization of the auditory belt areas in the chinchilla cortex remains unclear.

\subsection{Auditory Cortical Fields in Chiropterans}

Chiropterans are one of the most acoustically specialized mammalian orders. These animals have highly efficient acoustic sensory channels both for communication (i.e., for the processing of species-specific vocalizations) and for orien- 
tation behaviour when searching for prey (echolocation), which makes them especially interesting as a model for hearing physiology. Among all mammalian orders, different aspects of the morphofunctional organization of the auditory cortex in chiropterans were studied in the greatest detail, which is reflected in numerous studies of bats (Microchiroptera) [98]-[110].

The auditory cortex of different bat species contains from four to six auditory fields. The largest number of fields (six) was shown in the auditory cortex of the Phyllostomidae family [106] [107] [111]. The German neurobiologists Esser and Eiermann mapped the auditory cortex of the leaf-nosed bat (Carollia perspecilata) and defined six separate areas: four primary and two secondary auditory fields (Figure 4) [106] [107]. The authors referred to the primary auditory areas A1, AAF and the high-frequency field (HF), which contained neurons responding to tone frequencies in the range of $65-97 \mathrm{kHz}$. HF in turn was subdivided into two separate auditory fields (HFI and HFII) based on the differences in the distributions of the minimal neuronal response thresholds across these fields. As for the secondary auditory cortex in this animal, the secondary auditory field (A2) and dorsoposterior field (DP) were identified [106] [107].

The insectivore bats of the Microchiroptera suborder, such as the mustached bat, great horseshoe bat and little brown bat attracted the attention of neuroscientists due to their hunting behaviour based on the echolocation mechanism [98] [99] [101] [102] [104] [112]-[119]. Specific cortical organization in these animals is conditioned by its specialization to the processing of orientation calls, emitted by the bat itself during hunting, and orientation call reflections from multiple obstacles (i.e., echo signal). The temporal lobes of chiropterans are distinguished by their size among all neocortical formations. Their relative size in bats is much larger than in all other mammalian orders, which is directly related to the overrepresentation of the auditory system at the cortical level in these animals [102] [114] [120].

In the auditory cortex of insectivore bats, the primary auditory field (A1) contains several tonotopic areas. These areas have disproportionately large frequency representations of the orientation call, echo signal and the frequency ratios between them [101] [102] [109] [110] [121]-[126]. Anterior and posterior regions of A1 in the mustached bat and the central area DSCF located between them (famous for its concentric tonotopic structure) could be referred to as A1 "subfields" [109] [122]. The A1 is surrounded by several other auditory cortical areas involved in target movement processing. Tonotopy has not been shown in these fields [109] [122] [123] [124]. It is notable that the identification of different auditory cortical areas in bats was based rather on their functional specialization in echolocation than on the separation into primary and secondary areas.

\subsection{Auditory Cortical Fields in Other Mammalian Species}

In the rabbit auditory cortex, two primary auditory fields were identified: a large primary auditory field (A1) and a smaller secondary area located anterio-dorsally to A1 [35] [127] [128]. 


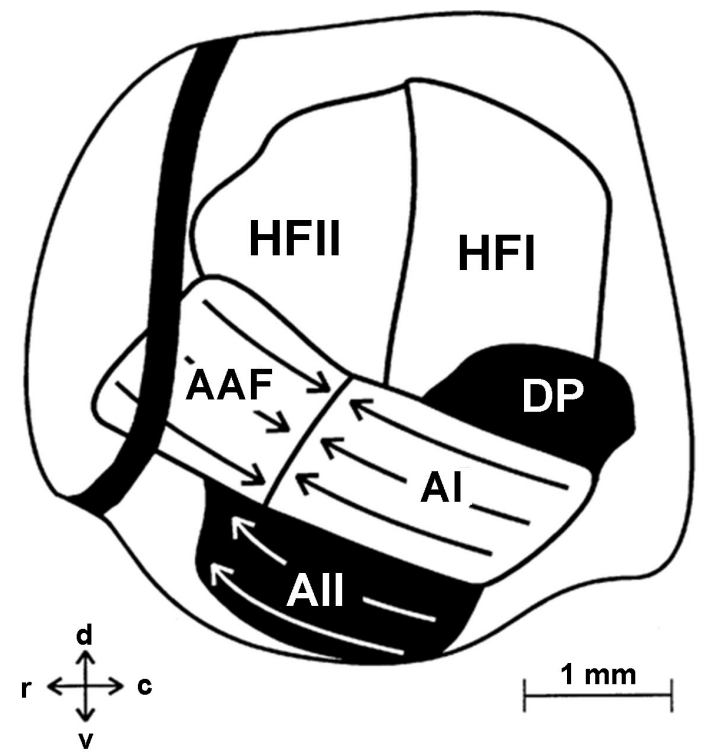

Figure 4. Auditory cortical fields of leaf-nosed bat Carollia perspecillata auditory cortex [107]. The primary auditory fields are: AI, AAF, HFI and HFII. The secondary auditory fields (AII and DP) are filled by black. The direction of frequencies increase in each tonotopically organized field is indicated by arrows. The dark line in the left part of figure is the blood vessel. $d$-dorsal direction, $\mathrm{v}$-ventral direction, $\mathrm{r}$-rostral direction, $\mathrm{c}$-caudal direction.

The organization of the auditory cortex in primates was clarified by the results of studies in New World monkeys [35] [129]-[134], Old World monkeys [36] [135]-[145], chimpanzee [35] [140] [146] [147] and galago [148] [149] [150] [151]. The main part of primate cortex where sound-evoked responses were recorded was the superior temporal gyrus, located deep within a lateral fissure (Figure 5). The primary auditory cortex is located along the inferior margin of the lateral sulcus. It contains three fields: primary auditory field (A1), rostral field (R) and rostrotemporal field (RT), all of which are elongated in the rostro-caudal direction in the sulcus plane. As in most of other mammals, A1 is located the most caudally. Field R is placed rostrally to A1, and field RT is located rostrally to field R [25] [40] [136] [138] [139] [148] [152] [153]. Primary auditory cortex in primates, due to its cytoarchitectonic properties and connectivity patterns, is regarded as a homological region of Brodmann's Area 41 in the human neocortex [25] [146] [147]. Within the primate secondary auditory belt surrounding primary auditory cortex, up to eight different fields are defined on the basis of their tonotopy, connections and architectonical features [25] [40] [138] [147].

The auditory parabelt in primates is identified ventrally to the secondary auditory fields near the superior temporal gyrus (STG, Figure 5) [40] [138] [139] [140]. The localization of STG borders wasn't clearly identified due to the absence of clear architectonical differences between the auditory belt and parabelt as well as the lack of detailed information about neuronal response properties 


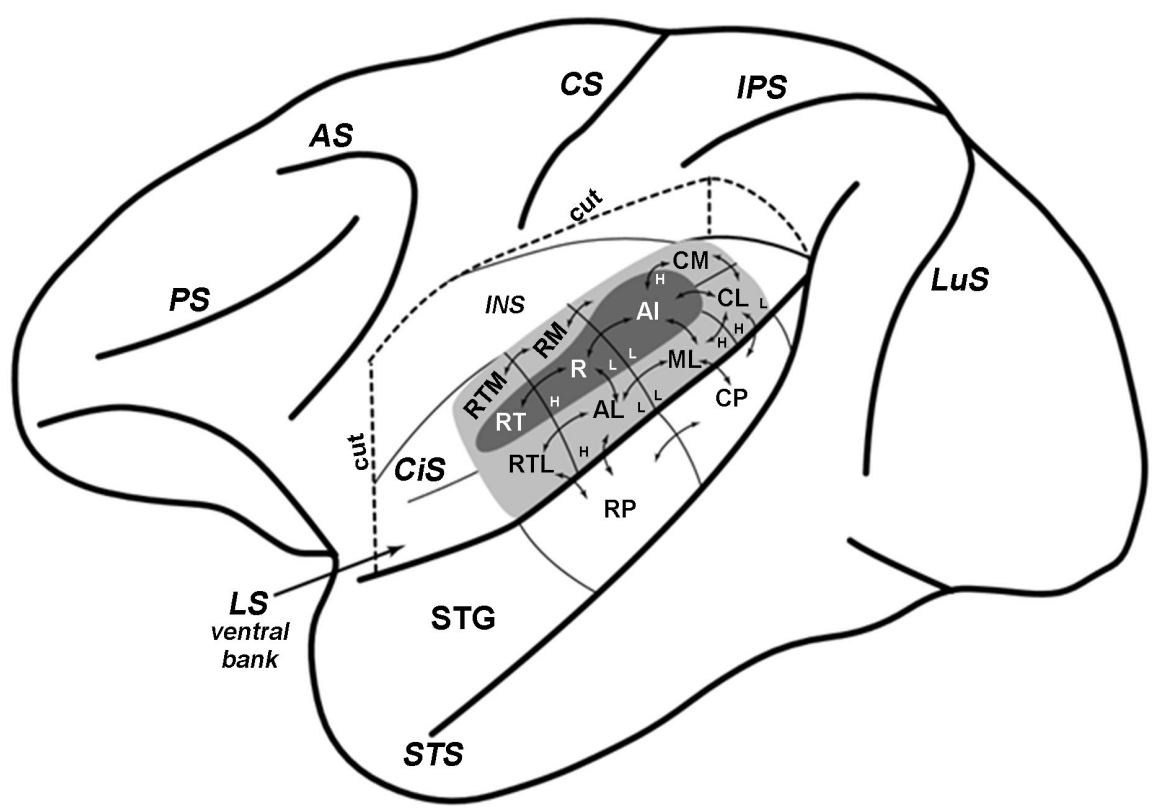

Figure 5. The scheme of macaque brain left hemisphere, demonstrating the location and intrinsic connections of auditory cortical fields [140]. The dorsal bank of lateral sulcus is removed to make available the superior temporal cortical zone (i.e. the ventral fringe of lateral sulcus). The floor and the outer bank of circular sulcus are smoothed to show the auditory fields located medially. The auditory core is filled by dark grey. AI-primary auditory field, R-rostral field, RT-rostrotemporal field. The auditory belt is shown by light grey filling. $\mathrm{CM}$-caudomedial belt, $\mathrm{CL}$-caudolateral belt, $\mathrm{ML}$ - medium lateral belt, $\mathrm{AL}$-anterolateral belt, RTL_rostrotemporolateral belt, RTM-rostrotemporomedial belt, $\mathrm{RM}-$ rostromedial secondary auditory area. The auditory parabelt is not colored. The parabelt area occupies the surface of superior temporal gyrus (STG), exposed on this scheme, and consists of rostral parabelt (RP) and caudal parabelt (CP). The core fields are projecting to the surrounding auditory belt (the direction of their efferents is indicated by arrows). The inputs, received by parabelt from lateral and medial auditory belt, are also shown by arrows. Connections, occurring between auditory parabelt and secondary belt areas, located medially, are not illustrated to maintain the clarity of the scheme. The frequency gradients are indicated by characters $\mathrm{H}$ (high frequencies) and L (low frequencies). Abbreviations: PS-principal sulcus; AS-arcuate sulcus; CS-central sulcus; IPS—interparietal sulcus; LuS-lunate sulcus; STS—-superior temporal sulcus; LS-lateral sulcus; CiS—circular sulcus; INS—insular cortex.

in these areas. Hackett and colleagues subdivided the auditory parabelt into rostral (RP) and caudal (CP) subregions due to differences in connectivity of these areas [154]. The main part of the rostral parabelt projects to the rostral secondary auditory fields, whereas the connections of caudal parabelt were concentrated in the caudal region of secondary auditory cortex. However, there were not clear differences found in the connectivity of these two parabelt areas [40], [147].

\section{Connectivity of the Auditory Cortex}

The auditory cortical fields are connected with a number of subcortical structures by thalamocortical, corticothalamic, corticotectal and corticopontic path- 
ways, and also with other fields of the auditory cortex by corticocortical fibres. The methods of retrograde degeneration and tracer injections (i.e., the injection of fluorescent and radioactive labels or labelling by horse-radish peroxidase) were used for identifying pathways. Early studies of cat and primate auditory cortices included only tracer injections and weren't combined with electrophysiological mapping of the auditory cortex. Thus, the axonal terminals distribution in cortical fields and their functional maps couldn't be obtained in these studies [155]-[163]. Later, simultaneous auditory cortex electrophysiological mapping and anatomical connectivity studies in a single animal were performed. This approach revealed that both the set and the spatial distribution of afferent and efferent projections in the auditory cortex strictly correlated with the functional organization of the auditory cortex and with the properties of synaptic terminals of cortical neurons. A combination of auditory cortex microelectrode mapping and morphological studies of the auditory cortical field projections to thalamus [17] [53] [164] [165] [166] [167] [168], midbrain [164] [169] [170] [171] [172] [173] basal ganglia [174] and other auditory, sensory and associative neocortical areas [17] [53] [175] [176] [177] [178] [179] revealed two main properties of this connected system. First, auditory cortical connections are a highly-ordered cochleotopic system. Neurons tuned to similar characteristic frequencies (CFs) are strictly (often reciprocally) connected to each other forming a common network, whereas neurons responding to different CFs remain relatively isolated from each other. Second, the auditory cortical projections are both highly convergent pathways and highly divergent ones [25].

\subsection{Primary Auditory Cortex Connections}

The system of primary auditory cortex afferents and efferents is well-studied [17] [173] [179]. The scheme of the cat auditory cortex afferent projections is presented in Figure 6.

\subsubsection{Thalamic Projections to the Primary Auditory Cortex}

Studies of thalamic inputs to the auditory cortex showed that all primary auditory fields receive inputs from MGB [17] [167] [168] [179]. As mentioned above, A1 and AAF get direct inputs from the ventral MGB [17] [168] [179]. Lee and colleagues used retrograde tracing methods to label neurons in the cat $\mathrm{A} 1$ and AAF receiving afferents from ventral MGB and thalamic sources of these projections. The data showed that less than $2 \%$ of neurons were double-labelled in this study [17], which means that most MGB neurons project to A1 and AFF independently of each other. This independence of the thalamic afferents of primary auditory fields assumes that A1 and AAF neurons tune to similar sound frequencies, and the MGB units projecting to these fields are parts of two parallel thalamocortical systems of connections providing acoustic information transfer to the integrative auditory centres [17] [179]. The projections from tonotopically organized ventral MGB account for more than $80 \%$ of A1 thalamic afferents [179]. AAF essentially differs from A1 in the organization of its thalamic 


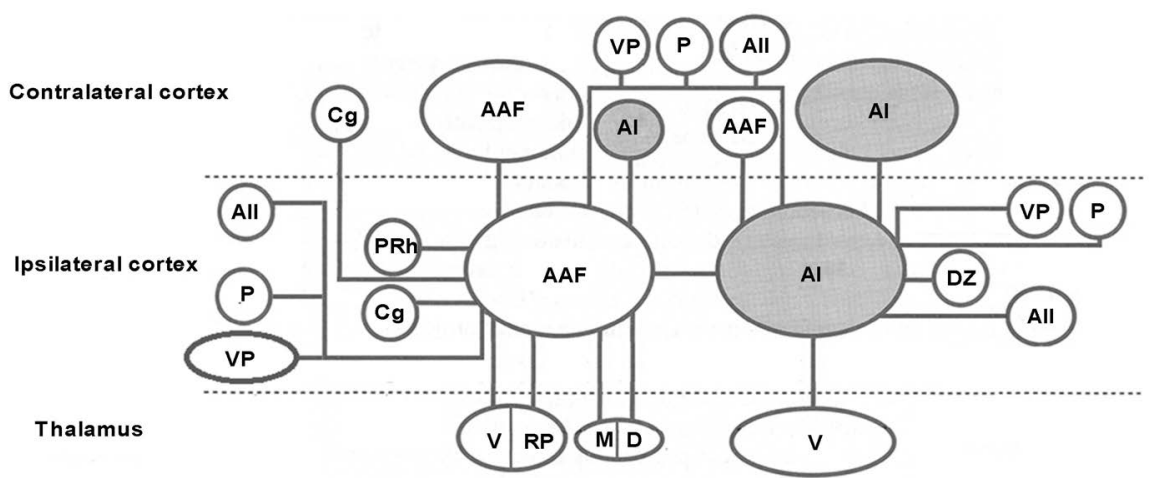

Figure 6. The main afferent projections received by the cat AI and AAF, rising from thalamic nuclei and cortical areas. The difference between AI and AAF in the set of their afferents is shown. Cortical sources of primary AC afferents are: ventroposterior auditory field (VP), posterior auditory field (P), secondary auditory field (AII), perirhinal cortex $(\mathrm{PRh})$, cingular cortex $(\mathrm{Cg})$ and auditory dorsal zone (DZ). Thalamic nuclei, projecting to the primary AC, are: ventral MGB (V), medial MGB (M), dorsal MGB (D) and MGB rostral pole (RP, the lateral part of thalamic nuclei posterior group). The area of each contour is proportional to the relative strength of the projections from each of thalamic or cortical source. Dashed lines divide projection sources (thalamus, ipsilateral cortex, contralateral cortex). AI is shown by grey filling. Modified from: [179].

afferents (Figure 6). About $75 \%$ of the AAF projections come from tonotopically organized ventral and rostral MGB regions, which are also called the lateral part of caudal thalamic nuclei [180]. A quarter of thalamic inputs to AAF are formed by projections from dorsal and medial MGB regions, where ordered tonotopy wasn't found [17]. It seems that the differences in thalamic afferentation found between A1 and AAF partially explain the different neuronal properties, which was revealed in these fields by Imaizumi and colleagues [179] [181].

The organization of thalamic inputs to the primary auditory cortex in mice was studied by using different types of retrograde tracers such as biotinylated dextran amine (BDA) and Alexa fluor-conjugated cholera toxin B subunit (CTB) [90] [182] [183]. The data obtained in these studies showed that A1 receives thalamic inputs mainly from the middle part of the ventral MGB region, whereas DM receives projections from the rostral compartment of the ventral MGB region [90] [183]. Tsukano and colleagues also reported that the ventral MGB neurons projecting to A1 were distributed along the dorsoventral axis, while the ventral MGB neurons projecting to the DM were topographically distributed along the ventrolateral-dorsomedial axis [90]. Horie and colleagues injected BDA into different parts of the mouse AAF in regard to previously identified tonotopic organization of this field and showed that the majority of labelled MGB neurons were located in the medial compartment of ventral MGB [183]. They also reported that neurons of the ventral MGB region projecting to the AAF were located along the mediolateral axis differing from the units projecting to the A1, which were distributed along the dorsoventral axis [183].

\subsubsection{Corticocortical Projections in Primary Auditory Fields}

Except the ascending projections from brainstem structures, A1 and AAF re- 
ceive various excitatory and inhibitory afferent inputs from other cortical regions including secondary auditory fields, sensory cortices of other modalities, associative areas and limbic cortex [17] [53] [179] [184]. In cats, strong projections to A1 and AAF from both ipsilateral and contralateral P, VP and A2 areas were shown [17] (Figure 6). It was found that the ipsilateral DZ in the cat auditory cortex is reciprocally connected with A1 [53] [179] (Figure 6). Shmigidina revealed the direct projections connecting rat primary auditory cortical area with both rostral and caudal regions of cingular cortex [175] (Figure 6). In addition, the vast afferent inputs to the rat AAF from perirhinal cortex, which is probably involved in learning and memory, were described by Lindquist and colleagues [185] (Figure 6).

The neurons in $\mathrm{A} 1$ and $\mathrm{AAF}$ receive strong afferents from the corresponding areas of the contralateral hemisphere, with the $\mathrm{A} 1$ units mainly projecting to the contralateral A1, and AAF neurons projecting their afferents to the contralateral AAF [17] (Figure 6). The evidence of high-ordered spatial distribution of connections within the auditory cortex was first obtained in a study of the cat auditory cortex, which showed that the electrical stimulation of certain cortical regions in one field evoked the response in a restricted area of another field [186]. Later, the organization of the main corticocortical pathways was studied in detail by electrophysiological recordings of sound-evoked single neurons' responses followed by the labelling of studied projections [176] [177]. Imig and Brugge electrophysiologically mapped large regions of cat A1, AAF, P and A2 simultaneously by injecting small amounts of the radioactive labelled proline in A1 along the $7.5 \mathrm{kHz}$ isofrequency contour. After injection, the radioactive label was found in AAF and $\mathrm{P}$ regions with neurons tuned to $7.5 \mathrm{kHz}$ [176]. These results revealed two properties of corticocortical auditory pathways. First, corticocortical connections are topographic-A1 neurons address their projections to the $\mathrm{AAF}$ and $\mathrm{P}$ units tuned to similar CFs. Second, corticocortical projections are divergent. A single injection of a small amount of radioactive proline in A1 was followed by the axons' labelling along the whole length of the isofrequency contour.

In another study, small doses of labelled proline were injected into the AAF and $\mathrm{P}$ regions in which the preliminary electrophysiological mapping of neuronal frequency tuning was performed. In both cases, the non-homogeneous distribution of the AAF and P projections occurred only in certain zones of the A1 field where the representations of corresponding frequencies were located. The clearly non-homogeneous distribution of corticocortical connections was shown after the injection of significant doses of labelled proline into the contralateral A1 [25].

Bizley and colleagues studied in detail the set and spatial distribution of corticocortical projections in different auditory cortical fields of ferrets [58]. The labelling by anterograde and retrograde tracers allowed the identification of large reciprocal fibres connecting ferret $\mathrm{A} 1$ and AAF with each other and with auditory belt areas. The strongest connections were found between ipsilateral A1 and 
AAF. In addition, Bizley and colleagues reported that A1 neurons are mainly projected to the belt areas in the posterior ectosylvian gyrus, whereas the AAF units project to the secondary auditory areas located close to both caudal and rostral ectosylvian gyrus [58]. Based on the differences obtained for the A1 and AAF projections to other auditory fields of ferret cortex, it was suggested that there are two independent pathways of acoustic information processing. A1 is involved with one of them, and AAF is involved with another [17] [58].

\subsubsection{Internal Connections within the Primary Auditory Fields}

Primary auditory cortex neurons are connected with each other by a set of internal pathways, and distribution within the primary fields corresponds to their tonotopic organization. Labelling of internal connections in the cat A1 with horse-radish peroxidase showed that the majority of labelled fibres were observed along the isofrequency contours [187] [188]. In addition, neurons of cat A1 located in the medial ectosylvian gyrus had branched dendrites oriented along the dorsoventral axis [187].

Anatomical studies of the primary auditory cortex cellular structure and cortical external and internal connectivity showed that, in addition to the horizontal ordering of the auditory cortex structure (i.e., cortical layers), there is a high-ordered vertical system of cortical neurons from all layers which are combined into vertically oriented groups of cells [161]. The vertically-oriented cellular group with weak horizontal connectivity consisting of cells from different cortical layers interconnected by vast projections along the vertical axis was named a "vertical column of neocortex". The term "column" at the first time was used by von Economo and Koskinas for the definition of the vertical rows of neocortical cells [189]. Lorento de No first suggested the vertical model of neocortical organization based on the results of his own study of interneuronal connectivity within the neocortex made by the Golgi method of tissue staining [190]. Vertical columns are shown for a wide variety of neocortical areas and therefore are the universal principle of cerebral cortex structural organization. The results of many electrophysiological experiments have shown that the vertical cellular column is a main functional unit in the auditory cortex underlying the importance of columnar organization studies for understanding the mechanisms of acoustic information cortical processing [99] [135] [191] [192]. It seems more reasonable to consider in greater detail the morpho-functional organization of cortical columns as functional units of primary and secondary auditory fields when describing a functional organization of these areas.

\subsubsection{Corticotectal Projections}

The results of studies of interconnections between the cat auditory cortex and auditory midbrain [164] [193] closely correspond to the data obtained in later studies of corticotectal connectivity in different animals [169] [170] [171] [172] [173] [194] [195]. Corticotectal pathways are both divergent and convergent as well as strictly tonotopically organized. These projections most likely start from 
the VI layer of neocortex [173]. It was shown in a cat [196] [197] and several species of rodents (guinea pig [169] [173], rat [194] [198], gerbil [199] and mouse [200]) that the A1 efferents project to the dorsomedial region of the ipsilateral inferior colliculus in the same way as in primates [8]. The contralateral inferior colliculus central nucleus (ICC) also receives inputs from A1, but they are weaker than ipsilateral ones [8]. The important property of the corticotectal connectivity system is the highly-ordered spatial distribution of projections corresponding to tonotopic organization observed in A1 and ICC.

\subsubsection{Ultrasound Field Connections}

The primary auditory cortex area containing neurons sensible to ultrasound was first observed in the auditory cortex of the echolocating mustached bat. This area was named the DSCF region. Neurons in this region were tuned to the second harmonic of the echo-signal (i.e., to frequencies of about $61 \mathrm{kHz}$ ) [101] [104] [114].

The areas of the mustached bat auditory cortex containing neurons tuned to high sound frequencies, especially regions specialized to the processing of the location call harmonic component (so-called CF-CF area), have an enormous set of afferents originating from different structures [201]. Namely, the CF-CF area receives afferent inputs from several subdivisions of $M G B$, the thalamic part of the reticular formation, striatum, pontine nuclei and claustrum as well as weaker inputs from both the inferior and superior colliculi, periaqueductal grey, pretectal region, intralaminar thalamic nuclei and the frontal lobe of the neocortex. In addition, connections of this area with other auditory cortical fields were shown-for example, with the FM-FM area specialized to analysis of frequency-modulated components of location call and with contralateral the CF-CF area [201]. In other chiropterans, connectivity in the auditory cortex ultrasound fields is poorly studied.

The second experimental subject using ultrasounds channel for communication with natural environments is the house mouse. UF of the mouse auditory cortex receives a large set of afferent projections. Most of them are inputs from the ipsilateral and contralateral MGB, ipsilateral primary and secondary auditory cortex and afferents from the contralateral UF field [69]. Furthermore, the weak efferent projections from sensory cortical areas of other modalities (e.g., somatosensory cortex) and from dorsal associative cortex are also addressed to the mouse UF [69].

\subsection{Secondary Auditory Cortex Connections}

As mentioned above, the set of afferent inputs to secondary auditory fields along with their cytoarchitectonics are the main criteria by which the auditory belt areas are distinguished from the core and parabelt areas. Connections of the secondary auditory fields differ in diffuse spatial distribution and in a high diversity of their sources.

The study of the auditory belt afferents in cats showed that its P and VP fields 
receive thalamic inputs from the thalamus ventral nucleus and medial MGB [177] [202] [203]. Projections of ventral MGB to P and VP are much weaker than ones addressed to the primary auditory fields. At the same time, pathways originating from the nuclei surrounding the ventral MGB region along its dorsal, caudal and ventral borders are relatively powerful. A2 receives thalamic inputs from several groups of MGB nuclei, including the ventrolateral nucleus and the caudal part of the dorsal nucleus. Projections of the medial MGB nucleus to A2 have also been shown [17] [25].

Furthermore, it was shown that the auditory belt areas are connected with the primary auditory fields, associative cortex, limbic cortical area and with each other by vast corticocortical projections [184]. Thus, the cat A2 field receives large afferent inputs from all tonotopically organized primary auditory areas, weak projections from $\mathrm{P}$ and inputs from temporal and insulate areas of limbic cortex. The P field receives inputs from A1, AAF and VP as well as weak and diffuse projections from $\mathrm{A} 2, \mathrm{DZ}$, temporal and insulate cortex and from the posterior ectosylvian gyrus [184]. It is noteworthy that in cats, the strongest connections between the primary and secondary auditory cortex were described for tonotopically organized primary and secondary areas, which are likely interconnected by the powerful system of reciprocal projections [17].

\subsection{Corticostriatal Connections}

Reale and Imig in 1983 determined the set and distribution of projections addressed by different areas of cat auditory cortex (A1, AAF, P and VP) to basal ganglia [188]. They showed that A1 and AAF neurons representing all frequency ranges of cats' hearing project to dorsal striatum regions (i.e., to caudate nucleus and putamen). Efferents of the P field were observed in the caudate nucleus, putamen and amygdala lateral nucleus. Neurons tuned to low and middle frequencies sent their axons to the caudate nucleus. Neurons tuned to high and middle frequencies addressed their projections to the amygdala lateral nucleus. The axons of neurons responding to all sound frequencies presented in the P field were addressed to the putamen. Projections of the VP field represented the whole frequency range of VP. They terminated on neurons of the ventral putamen and the amygdala lateral nucleus. There were not any axons of VP neurons found in the caudate nucleus [188].

\section{Conclusion}

In summary, based on the analysis of the auditory cortical fields' structure in different mammalian species, we obviously can argue about common principles of their organization in studied animals. At the same time, the diversity of topographical features and numbers of the auditory cortical fields has been shown even in closely-related mammalian taxa. This diversity might occur due to the imperfection in criteria used for separate auditory field definitions as well as the high plasticity of neocortical neurons. 


\section{Acknowledgements}

This work was supported by RFBR (projects No. 12-04-00969 and 18-15-00188) and state budget for 2018-2020 (reg. No. AAAA-A18-118013090245-6).

\section{Conflicts of Interest}

The authors declare no conflicts of interest regarding the publication of this paper.

\section{References}

[1] Carbajal, G.V. and Malmierca, M.S. (2018) The Unique Role of the Non-Lemniscal Pathway on Stimulus-Specific Adaptation (SSA) in the Auditory System. Proceedings of International Symposium on Auditory and Audiological Research, 6, 95-106.

[2] Serkov, F.N. (1977) Electrophysiology of Higher Levels of the Auditory System. Naukova Dumka, Kiev. (In Russian)

[3] Serkov, F.N. (1986) Cortical Inhibition. Naukova Dumka, Kiev. (In Russian)

[4] Vartanian, I.A. (1978) Slukhovoi analiz slozhnykh zvukov (Auditory Analysis of Complex Sounds). Nauka, Leningrad. (In Russian)

[5] Vartanian, I.A. and Shmigidina, G.N. (1991) The Structural-Functional Organization of the Auditory Cortex in Rats. Zhurnal evoliutsionnoi biokhimii i fiziologii, 27, 344-350. (In Russian)

[6] Egorova, M.A. (2005) Frequency Selectivity of Neurons of the Primary Auditory Field (A1) and Anterior Auditory Field (AAF) in the Auditory Cortex of the House Mouse (Mus musculus). Journal of Evolutionary Biochemistry and Physiology, 41, 379-382. https://doi.org/10.1007/s10893-005-0085-4

[7] Tunturi, A.R. (1960) Anatomy and Physiology of the Auditory Cortex. In: Thomas, C.C., Eds., Neural Mechanisms of the Auditory and Vestibular Systems, Springfield, Illinois, 181-200.

[8] Rockel, A.J. and Jones, E.G. (1973) The Neuronal Organization of the Inferior Colliculus of the Adult Cat. I. The Central Nucleus. Journal of Comparative Neurology, 147, 11-60. https://doi.org/10.1002/cne.901470103

[9] Reale, R.A. and Imig, T.J. (1980) Tonotopic Organization in Auditory Cortex of the Cat. Journal of Comparative Neurology, 192, 265-291. https://doi.org/10.1002/cne.901920207

[10] Redies, H., Sieben, U. and Creutzfeldt, O.D. (1989) Functional Subdivisions in the Auditory Cortex of the Guinea Pig. Journal of Comparative Neurology, 282, 473-488. https://doi.org/10.1002/cne.902820402

[11] Haase, H. and Ehret, G. (1990) Lateralization of Sound Perception in the Brain of the Mouse (Mus musculus) In: Perception-Cognition: Proceedings of the 18 th Goettingen Neurobiological Conference, Thieme Verlag, Stuttgart, 150-151.

[12] Thomas, H., Tillein, J., Heil, P. and Scheich, H. (1993) Functional Organization of Auditory Cortex in the Mongolian Gerbil (Meriones unguiculatus). I. Electrophysiological Mapping of Frequency Representation and Distinction of Fields. European Journal of Neuroscience, 5, 882-897. https://doi.org/10.1111/j.1460-9568.1993.tb00940.x

[13] Stiebler, I., Neulist, R., Fichtel, I. and Ehret, G. (1997) The Auditory Cortex of the House Mouse: Left-Right Differences, Tonotopic Organization and Quantitative 
Analysis of Frequency Representation. Journal of Comparative Physiology A, 181, 559-571. https://doi.org/10.1007/s003590050140

[14] Wallace, M.N., Rutkowski, R.G. and Palmer, A.R. (2000) Identification and Localization of Auditory Areas in Guinea Pig Cortex. Experimental Brain Research, 132, 445-456. https://doi.org/10.1007/s002210000362

[15] Loftus, W.C. and Sutter, M.L. (2001) Spectrotemporal Organization of Excitatory and Inhibitory Receptive Fields of Cat Posterior Auditory Field Neurons. Journal of Neurophysiology, 86, 475-491. https://doi.org/10.1152/jn.2001.86.1.475

[16] Linden, J.F., Liu, R.C., Sahani, M. and Schreiner, C.E. (2003) Spectrotemporal Structure of Receptive Fields in Areas AI and AAF of Mouse Auditory Cortex. Journal of Neurophysiology, 90, 2660-2675. https://doi.org/10.1152/jn.00751.2002

[17] Lee, C.C., Imaizumi, K., Schreiner, C.E. and Winer, J.A. (2004) Concurrent Tonotopic Processing Streams in Auditory Cortex. Cerebral Cortex, 14, 441-451. https://doi.org/10.1093/cercor/bhh006

[18] Bizley, J.K., Nodal, F.R., Nelken, I. and King, A.J. (2005) Functional Organization of Ferret Auditory Cortex. Cerebral Cortex, 15, 1637-1653. https://doi.org/10.1093/cercor/bhi042

[19] Taniguchi, I., Sugimoto, S., Hess, A., Horikawa, J., Hosokawa, Y. and Scheich, H. (2005) Spatio-Temporal Pattern in the Guinea Pig Auditory Cortex. In: Auditory Cortex: A Synthesis of Human and Animal Research, Lawrence Erlbaum Associates Inc., Mahwah-London, 315-330.

[20] Christianson, G.B., Sahani, M. and Linden, J.F. (2011) Depth-Dependent Temporal Response Properties in Core Auditory Cortex. Journal of Neuroscience, 31, 12837-12848. https://doi.org/10.1523/JNEUROSCI.2863-11.2011

[21] Woolsey, C.N. and Walzl, E.M. (1942) Topical Projection of Nerve Fibres from Local Regions of the Cochlea to the Cerebral Cortex of the Cat. Bulletin of the Johns Hopkins Hospital, 71, 315-344.

[22] Woolsey, C.N. (1960) Organization of Cortical Auditory System: A Review and a Synthesis. In: Rasmussen, G.L. and Windle, W.F., Eds., Neural Mechanisms of the Auditory and Vestibular Systems, Charles C Thomas, Springfield, IL, 165-180.

[23] Woolsey, C.N. (1961) Organization of Cortical Auditory System. In: Rosenblith, W.A., Ed., Sensory Communication, MIT Press, Cambridge, MA, 235-257.

[24] O’Connel, M., Falchier, A., McGinnis, T., Schroeder, C.E. and Lakatos, P. (2011) Dual Mechanism of Neuronal Ensemble Inhibition in Primary Auditory Cortex. Neuron, 69, 805-817. https://doi.org/10.1016/j.neuron.2011.01.012

[25] Brugge, J.F. and Reale, R.A (1985) Auditory Cortex. In: Peters, A. and Jones, E.G., Eds., Cerebral Cortex, Plenum Press, New York, 229-271. https://doi.org/10.1007/978-1-4757-9619-3_6

[26] Campbell, A.W. (1905) Histological Studies on the Localization of Cerebral Function. Cambridge University Press, Cambridge.

[27] Kornmüller, A.E. (1937) Die bioelektrischen Erscheinungen der Hirnrindenfelder: mit allgemeineren Ergebnissen zur Physiologie und Pathophysiologie des zentralnervösen Griseum. Georg Thieme Verlag. (In German)

[28] Bremer, F. and Dow, R.S. (1939) The Cerebral Acoustic Area of the Cat. A Combined Oscillographic and Cytoarchitectonic Study. Journal of Neurophysiology, 2, 308-318. https://doi.org/10.1152/jn.1939.2.4.308

[29] Woolsey, C.N. (1982) Cortical Sensory Organization: Multiple Auditory Areas. Humana Press, New York, 3. 
[30] Rose, J.E. (1949) The Cellular Structure of the Auditory Region of the Cat. Journal of Comparative Neurology, 91, 409-439. https://doi.org/10.1002/cne.900910305

[31] Rose, J.E. and Woolsey, C.N. (1949) Organization of the Mammalian Thalamus and Its Relationships to the Cerebral Cortex. Electroencephalography and Clinical Neurophysiology, 1, 391-404. https://doi.org/10.1016/0013-4694(49)90212-6

[32] Rose, J.E. and Woolsey, C.N. (1958) Cortical Connections and Functional Organization of Thalamic Auditory System in the Cat. In: Harlow, H.F. and Woolsey, C.N., Eds., Biological and Biochemical Bases of Behavior, University of Wisconsin Press, Madison, 127-150.

[33] Hind, J.E., Benjamin, R.M. and Woolsey, C.N. (1958) Auditory Cortex of the Squirrel Monkey (Saimiri sciureus). Federation Proceedings, 17, 71.

[34] Woolsey, C.N., Adrian, H. and Lifschitz, W. (1964) Activity of Neuronal Units in the Auditory area of the Cerebellum of Decerebrate Cats. Science, 146, 435-436.

[35] Woolsey, C.N. (1971) Tonotopic Organization of the Auditory Cortex. In: Sachs, M.B., Ed., Physiology of the Auditory System: A Workshop, National Educational Consultants, Baltimore, 271-282.

[36] Woolsey, C.N. and Walzl, E.M. (1982) Cortical Auditory Area of Macaca mulatta and Its Relation to the Second Somatic Sensory Area (Sm II). In: Woolsey, C.N., Ed., Cortical Sensory Organization, Humana Press, Totowa, NJ, 231-256. https://doi.org/10.1007/978-1-4612-5817-9_8

[37] Graybiel, A.M. (1973) The Thalamo-Cortical Projection of the So-Called Posterior Nuclear Group: A Study with Anterograde Degeneration Methods in the Cat. Brain Research, 49, 229-244. https://doi.org/10.1016/0006-8993(73)90420-4

[38] Graybiel, A.M. (1974) Studies on the Anatomical Organization of Posterior Assotiation Cortex. In: The Neurosciences Third Study Program, The MIT Press, Cambridge, 205-214.

[39] Phillips, D.P. and Irvine, D.R.F. (1982) Properties of Single Neurons in the Anterior Auditory Field (AAF) of Cat Cerebral Cortex. Brain Research, 248, 237-244. https://doi.org/10.1016/0006-8993(82)90581-9

[40] Kaas, J.H. and Hackett, T.A. (2005) Subdivisions and Connections of Auditory Cortex in Primates: A Working Model. In: Auditory Cortex. A Synthesis of Human and Animal Research, Lawrence Erlbaum Associates Inc., Mahwah-London, 7-26.

[41] Kanwal, J.S. and Ehret, G. (2010) Communication Sounds and Their Cortical Representation. In: The Auditory Cortex, Springer, New York, 343-368.

[42] Gates, G.R. and Aitkin, L.M. (1982) Auditory Cortex in the Marsupial Possum, Trichosurus vulpecula. Hearing Research, 7, 1-11. https://doi.org/10.1016/0378-5955(82)90078-8

[43] Aitkin, L.M., Irvine, D.R.F., Nelson, J.E., Merzenich, M.M. and Clarey, J.C. (1986) Frequency Representation in the Auditory Midbrain and Forebrain of a Marsupial, the Northern Native Cat (Dasyurus hallucatus). Brain, Behavior and Evolution, 29, 17-28. https://doi.org/10.1159/000118669

[44] Batzri-Izraeli, R., Kelly, J.B., Glendenning, K.K., Masterton, R.B. and Wollberg, Z. (1990) Auditory Cortex of the Long-Eared Hedgehog (Hemiechinus auritus): I. Boundaries and Frequency Representation. Brain, Behavior and Evolution, 36, 237-248. https://doi.org/10.1159/000115310

[45] Catania, K.C., Collins, C.E. and Kaas, J.H. (2000) Organization of Sensory Cortex in the East African Hedgehog (Atelerix albiventris). Journal of Comparative Neurology, 421, 256-274. 
https://doi.org/10.1002/(SICI)1096-9861(20000529)421:2<256::AID-CNE10>3.0.CO $\underline{; 2-\mathrm{Y}}$

[46] Catania, K.C. (2005) Evolution of Sensory Specializations in Insectivores. The Anatomical Record. Part A, Discoveries in Molecular, Cellular, and Evolutionary Biology, 287A, 1038-1050. https://doi.org/10.1002/ar.a.20265

[47] Goldberg, J., Diamond, I. and Neff, W. (1957) Auditory Discrimination after Ablation of Temporal and Insular Cortex in Cat. Federation Proceedings, 16, 204-205.

[48] Thompson, R.F. and Sindberg, R.M. (1960) Auditory Response Fields in Association and Motor Cortex of Cat. Journal of Neurophysiology, 23, 87-105. https://doi.org/10.1152/jn.1960.23.1.87

[49] Imig, T.J. and Morel, A. (1983) Organization of the Thalamocortical Auditory System in the Cat. Annual Review of Neuroscience, 6, 95-120. https://doi.org/10.1146/annurev.ne.06.030183.000523

[50] Read, H.L., Winer, J.A. and Schreiner, C.E. (2002) Functional Architecture of Auditory Cortex. Current Opinion in Neurobiology, 12, 433-440. https://doi.org/10.1016/S0959-4388(02)00342-2

[51] Hall, A.J. (2015) Hierarchical Organization in Auditory Cortex of the Cat Using High-Field Functional Magnetic Resonance Imaging. PhD Thesis, Western University, London, Ontario, Canada.

[52] Knight, P.L. (1977) Representation of the Cochlea within the Anterior Auditory Field (AAF) of the Cat. Brain Research, 130, 447-467. https://doi.org/10.1016/0006-8993(77)90108-1

[53] Middlebrooks, J.C. and Zook, J.M. (1983) Intrinsic Organization of the Cat's Medial Geniculate Body Defined by Projections to Binaural Response-Specific Bands in the Primary Auditory Cortex. Journal of Neuroscience, 3, 203-224. https://doi.org/10.1523/JNEUROSCI.03-01-00203.1983

[54] Wallace, M.N., Roeda, D. and Harper, M.S. (1997) Deoxyglucose Uptake in the Ferret Auditory Cortex. Experimental Brain Research, 117, 488-500. https://doi.org/10.1007/s002210050245

[55] Kelly, J.B., Judge, P.W. and Phillips, D.P. (1986) Representation of the Cochlea in Primary Auditory Cortex of the Ferret (Mustela putorius). Hearing Research, 24, 111-115. https://doi.org/10.1016/0378-5955(86)90054-7

[56] Kelly, J.B. and Judge, P.W. (1994) Binaural Organization of Primary Auditory Cortex in the Ferret (Mustela putorius). Journal of Neurophysiology, 71, 904-913. https://doi.org/10.1152/jn.1994.71.3.904

[57] Nelken, I., Bizley, J.K., Nodal, F.R., Ahmed, B., Schnupp, J.W.H. and King, A.J. (2004) Large-Scale Organization of Ferret Auditory Cortex Revealed Using Continuous Acquisition of Intrinsic Optical Signals. Journal of Neurophysiology, 92, 2574-2588. https://doi.org/10.1152/jn.00276.2004

[58] Bizley, J.K., Bajo, V.M., Nodal, F.R. and King, A.J. (2015) Cortico-Cortical Connectivity within Ferret Auditory Cortex. Journal of Comparative Neurology, 523, 2187-2210. https://doi.org/10.1002/cne.23784

[59] Krieg, W.J.S. (1946) Connections of Cerebral Cortex. I. The Albino Rat. A. Topography of the Cortical Areas. Journal of Comparative Neurology, 84, 221-275. https://doi.org/10.1002/cne.900840205

[60] Vartanyan, I.A. and Shmigidina, G.N. (1972) Impulse Neuronal Activity in the Auditory Cortex of Rats during the Effect of Sound Signals. Journal of Evolutionary Biochemistry and Physiology, 8, 67-77. 
[61] Vartanyan, I.A. and Shmigidina, G.N. (1995) Neurobiological Basis for Acoustical Communication. Comparative Physiological Review of Structures and Mechanisms. Journal of Evolutionary Biochemistry and Physiology, 31, 677-684.

[62] Zilles, K., Zilles, B. and Schleicher, A. (1980) A Quantitative Approach to Cytoarchitectonics. VI. The Areal Pattern of the Cortex of the Albino-Rat. Anatomy and Embryology, 159, 335-360. https://doi.org/10.1007/BF00317655

[63] Sally, S.L. and Kelly, J.B. (1988) Organization of Auditory Cortex in the Albino Rat: Sound Frequency. Journal of Neurophysiology, 59, 1627-1638. https://doi.org/10.1152/jn.1988.59.5.1627

[64] Villa, A.E.P. (2005) Spatio-Temporal Patterns of Spike Occurrences in Freely-Moving Rats Associated to Perception of Human Vowels. In: König, R., Heil, P., Budinger, E. and Scheich, H., Eds., Auditory Cortex. Towards a Synthesis of Human and Animal Research, Lawrence Erlbaum Associates Inc., Mahwah-London, 275-293.

[65] Polley, D.B., Read, H.L., Storace, D.A. and Merzenich, M.M. (2007) Multiparametric Auditory Receptive Field Organization across Five Cortical Fields in the Albino Rat. Journal of Neurophysiology, 97, 3621-3638. https://doi.org/10.1152/jn.01298.2006

[66] Caviness, V.S. (1975) Architectonic Map of Neocortex of the Normal Mouse. Journal of Comparative Neurology, 164, 247-263. https://doi.org/10.1002/cne.901640207

[67] Ehret, G. (1987) Left Hemisphere Advantage in the Mouse Brain for Recognizing Ultrasonic Communication Calls. Nature, 325, 249-251. https://doi.org/10.1038/325249a0

[68] Stiebler, I. (1987) A Distinct Ultrasound-Processing Area in the Auditory Cortex of the Mouse. The Science of Nature, 74, 96-97. https://doi.org/10.1007/BF00366088

[69] Hofstetter, K.M. and Ehret, G. (1992) The Auditory Cortex of the Mouse: Connections of the Ultrasonic Field. Journal of Comparative Neurology, 323, 370-386. https://doi.org/10.1002/cne.903230306

[70] Willott, J.F., Aitkin, L.M. and McFadden, S.L. (1993) Plasticity of Auditory Cortex Associated with Sensorineural Hearing Loss in Adult C57BL/6J Mice. Journal of Comparative Neurology, 329, 402-411. https://doi.org/10.1002/cne.903290310

[71] Shen, J., Xu, Z. and Yao, Y. (2000) Topography of Acoustic Response Characteristics in the Auditory Cortex of the Kunming Mouse. Chinese Science Bulletin, 45, 443-448. https://doi.org/10.1007/BF02884948

[72] Malinina, E.S. (2005) Responses of Mouse Auditory Cortex Neurons to Signals with Regular Varying Spectrum. Sensory Systems, 19, 240-244. (In Russian)

[73] Malinina, E.S. (2006) Processing of Spectral Localization-Informative Changes in Sound Signals by Neurons of Inferior Colliculus and Auditory Cortex of the House Mouse Mus musculus. Journal of Evolutionary Biochemistry and Physiology, 42, 604-618. https://doi.org/10.1134/S0022093006050103

[74] Rothschild, G., Nelken, I. and Mizrahi1, A. (2010) Functional Organization and Population Dynamics in the Mouse Primary Auditory Cortex. Nature Neuroscience, 13, 353-362. https://doi.org/10.1038/nn.2484

[75] Schulze, H., Ohl, F.W., Heil, P. and Scheich, H. (1997) Field-Specific Responses in the Auditory Cortex of the Unanesthestized Mongolian Gerbil to Tones and Slow Frequency Modulations. Journal of Comparative Physiology A, 181, 573-589. https://doi.org/10.1007/s003590050141

[76] Richter, K., Hess, A. and Scheich, H. (1999) Functional Mapping of Transsynaptic 
Effects of Local Manipulation of Inhibition in Gerbil Auditory Cortex. Brain Research, 831, 184-199. https://doi.org/10.1016/S0006-8993(99)01440-7

[77] Hellweg, F.C., Koch, R. and Vollrath, M. (1977) Representation of the Cochlea in the Neocortex of Guinea Pigs. Experimental Brain Research, 29, 467-474.

https://doi.org/10.1007/BF00236184

[78] Wallace, M.N., Rutkowski, R.G. and Palmer, A.R. (1999) A Ventrodorsal Belt Is Adjacent to the Guinea Pig Primary Auditory Cortex. NeuroReport, 10, 2095-2099. https://doi.org/10.1097/00001756-199907130-00019

[79] Horikawa, J., Hosokawa, Y., Nasu, M. and Taniguchi, I. (1997) Optical Study of Spatiotemporal Inhibition Evoked by Two-Tone Stimuli in the Guinea Pig Auditory Cortex. Journal of Comparative Physiology A, 181, 677-684. https://doi.org/10.1007/s003590050149

[80] Horikawa, J., Hess, A., Nasu, M., Hosokawa, Y., Scheich, H. and Taniguchi, I. (2001) Optical Imaging of Neuronal Activity in Multiple Auditory Cortical Fields of Guinea Pigs. NeuroReport, 12, 3335-3339. https://doi.org/10.1097/00001756-200110290-00038

[81] Hosokawa, Y., Sugimoto, S., Kubota, M., Taniguchi, I. and Horikawa, J. (2004) Optical Imaging of Binaural Interaction in Multiple Fields of the Guinea Pig Auditory Cortex. NeuroReport, 15, 1093-1097. https://doi.org/10.1097/00001756-200405190-00002

[82] Kaas, J.H., Hall, W.C. and Diamond, I.T. (1972) Visual Cortex of the Grey Squirrel (Sciureus carolinensis): Architectonic Subdivisions and Connections from Visual Thalamus. Journal of Comparative Neurology, 145, 273-306. https://doi.org/10.1002/cne.901450303

[83] Merzenich, M.M., Kaas, J.H. and Roth, G.L. (1976) Auditory Cortex in the Grey Squirrel: Tonotopic Organization and Architectonic Fields. Journal of Comparative Neurology, 166, 387-401. https://doi.org/10.1002/cne.901660402

[84] Luethke, L.E., Krubitzer, L.A. and Kaas, J.H. (1988) Cortical Connections of Electrophysiologically and Architectonically Defined Subdivisions of Auditory Cortex in Squirrels. Journal of Comparative Neurology, 268, 181-203. https://doi.org/10.1002/cne.902680205

[85] Harrison, R.V., Kakigi, A., Hirakawa, H., Harel, N. and Mount, R.J. (1996) Tonotopic Mapping in Auditory Cortex of the Chinchilla. Hearing Research, 100, 157-163. https://doi.org/10.1016/0378-5955(96)00120-7

[86] Harel, N., Mori, N., Sawada, S., Mount, R.J. and Harrison, R.V. (2000) Three Distinct Auditory Areas of Cortex (AI, AII, and AAF) Defined by Optical Imaging of Intrinsic Signals. NeuroImage, 11, 302-312. https://doi.org/10.1006/nimg.1999.0537

[87] Pienkowski, M. and Harrison, R.V. (2005) Tone Frequency Maps and Receptive Fields in the Developing Chinchilla Auditory Cortex. Journal of Neurophysiology, 93, 454-466. https://doi.org/10.1152/jn.00569.2004

[88] Tsukano, H., Horie, M., Bo, T., Uchimura, A., Hishida, R., Kudoh, M., et al. (2015) Delineation of a Frequency-Organized Region Isolated from the Mouse Primary Auditory Cortex. Journal of Neurophysiology, 113, 2900-2920. https://doi.org/10.1152/jn.00932.2014

[89] Tsukano, H., Horie, M., Hishida, R., Takahashi, K., Takebayashi, H. and Shibuki, K. (2016) Quantitative Map of Multiple Auditory Cortical Regions with a Stereotaxic Fine-Scale Atlas of the Mouse Brain. Scientific Reports, 6, Article No. 22315. https://doi.org/10.1038/srep22315 
[90] Tsukano, H., Horie, M., Ohga, S., Takahashi, K., Kubota, Y., Hishida, R., et al. (2017) Reconsidering Tonotopic Maps in the Auditory Cortex and Lemniscal Auditory Thalamus in Mice. Frontiers in Neural Circuits, 11, 14.

[91] Rutkowski, R.G., Miasnikov, A.A. and Weinberger, N.M. (2003) Characterisation of Multiple Physiological Fields within the Anatomical Core of Rat Auditory Cortex. Hearing Research, 181, 116-130. https://doi.org/10.1016/S0378-5955(03)00182-5

[92] Pandya, P.K., Rathbun, D.L., Moucha, R., Engineer, N.D. and Kilgard, M.P. (2008) Spectral and Temporal Processing in Rat Posterior Auditory Cortex. Cerebral Cortex, 18, 301-314. https://doi.org/10.1093/cercor/bhm055

[93] Profant, O., Burianova, J. and Syka, J. (2013) The Response Properties of Neurons in Different Fields of the Auditory Cortex in the Rat. Hearing Research, 296, 51-59. https://doi.org/10.1016/j.heares.2012.11.021

[94] Zilles, K. and Wree, A. (1985) Cortex: Areal and Laminar Structure. In: The Rat Nervous System. Forebrain and Midbrain, Academic Press, New York, 375-392.

[95] Budinger, E., Heil, P. and Scheich, H. (2000) Functional Organization of Auditory Cortex in the Mongolian Gerbil (Meriones unguiculatus). IV. Connections with Anatomically Characterized Subcortical Structures. European Journal of Neuroscience, 12, 2452-2474. https://doi.org/10.1046/j.1460-9568.2000.00143.x

[96] Sakai, M. and Suga, N. (2002) Centripetal and Centrifugal Reorganizations of Frequency Map of Auditory Cortex in Gerbils. Proceedings of the National Academy of Sciences of the United States of America, 99, 7108-7112.

https://doi.org/10.1073/pnas.102165399

[97] Schulze, H., Hess, A., Ohl, F.W. and Scheich, H. (2002) Superposition of Horseshoe-Like Periodicity and Linear Tonotopic Maps in Auditory Cortex of the Mongolian Gerbil. European Journal of Neuroscience, 15, 1077-1084. https://doi.org/10.1046/j.1460-9568.2002.01935.x

[98] Suga, N. (1965) Functional Properties of Auditory Neurons in the Cortex of Echo-Locating Bats. The Journal of Physiology, 181, 671-700. https://doi.org/10.1113/jphysiol.1965.sp007791

[99] Suga, N. (1977) Amplitude Spectrum Representation in the Doppler-Shifted-CF Processing Area of the Auditory Cortex of the Mustache Bat. Science, 196, 64-67. https://doi.org/10.1126/science.190681

[100] Burikova, N.V. (1974) Cytoarchitectonics and Afferent Projections of Several Centers of the Auditory System in Bats. PhD Thesis, Leningrad State University, Leningrad. (In Russian)

[101] Suga, N. and Jen, P.H.S. (1976) Disproportionate Tonotopic Representation for Processing Species-Specific CF-FM Sonar Signals in the Mustache Bat Auditory Cortex. Science, 194, 542-544. https://doi.org/10.1126/science.973140

[102] Ostwald, J. (1980) The Functional Organization of the Auditory Cortex in the CF-FM Bat Rhinolophus ferrumequinum. In: Busnel, R.G. and Fish, J.F., Eds., Animal Sonar Systems, Plenum Press, New York, 953-955. https://doi.org/10.1007/978-1-4684-7254-7_66

[103] Ostwald, J. (1984) Tonotopical Organization and Pure Tone Response Characteristics of Single Units in the Auditory Cortex of the Greater Horseshoe Bat. Journal of Comparative Physiology A, 155, 821-834. https://doi.org/10.1007/BF00611599

[104] Suga, N., Kuzirai, K. and O’Neill, W.E. (1981) How Biosonar Information Is Represented in the Bat Cerebral Cortex. In: Syka, J. and Aitkin, L., Eds., Neuronal Mechanisms of Hearing, Plenum Press, New York, 197-219.

https://doi.org/10.1007/978-1-4684-3908-3_21 
[105] Esser, K.-H. and Kiefer, R. (1996) Detection of Frequency Modulation in the FM-Bat Phyllostomus discolor. Journal of Comparative Physiology A, 178, 787-796. https://doi.org/10.1007/BF00225827

[106] Eiermann, A. and Esser, K.-H. (1996) Tonotopic Organization and Parcellation of Auditory Cortex in the FM-Bat Carollia perspicillata. In: Elsner, N. and Schnitztler, H.-U. (Eds.), Göttingen Neurobiology Report. Proceedings of the 24th Göttingen Neurobiological Conference, Thieme Verlag, Stuttgart, 237.

[107] Esser, K.-H. and Eiermann, A. (1999) Tonotopic Organization and Parcellation of Auditory Cortex in the FM-Bat Carollia perspicillata. European Journal of Neuroscience, 11, 3669-3682. https://doi.org/10.1046/j.1460-9568.1999.00789.x

[108] Esser, K.H., Condon, C.J., Suga, N. and Kanwal, J. (1997) Syntax Processing by Auditory Cortical Neurons in the FM-FM Area of the Mustached Bat Pteronotus parnellii. Proceedings of the National Academy of Sciences of the United States of America, 94, 14019-14024. https://doi.org/10.1073/pnas.94.25.14019

[109] Kanwal, J.S., Fitzpatrick, D.C. and Suga, N. (1999) Facilitatory and Inhibitory Frequency Tuning of Combination-Sensitive Neurons in the Primary Auditory Cortex of Mustached Bats. Journal of Neurophysiology, 82, 2327-2345. https://doi.org/10.1152/jn.1999.82.5.2327

[110] Ma, X. and Suga, N.J. (2004) Lateral Inhibition for Center-Surround Reorganization of the Frequency Map of Bat Auditory Cortex. Journal of Neurophysiology, 92, 3192-3199. https://doi.org/10.1152/jn.00301.2004

[111] Hoffmann, S., Baier, L., Borina, F., Schuller, G., Wiegrebe, L. and Firzlaff, U. (2008) Psychophysical and Neurophysiological Hearing Thresholds in the Bat Phyllostomus discolor. Journal of Comparative Physiology A, 194, 39-47. https://doi.org/10.1007/s00359-007-0288-9

[112] Galambos, R. and Griffin, D.R. (1940) The Supersonic Cries of Bats. The Anatomical Record, 78, 95-96.

[113] Galambos, R. and Griffin, D.R. (1942) Obstacle Avoidance by Flying Bats: The Cries of Bats. Journal of Experimental Zoology, 89, 475-490. https://doi.org/10.1002/jez.1400890308

[114] Suga, N. (1988) Auditory Neuroethology and Speech Processing: Complex Sound Processing by Combination-Sensitive Neurons. In: Edelman, G.M., Gall, W.E. and Cowan, W.M., Eds., Auditory Function. Neurobiological Bases of Hearing, John Wiley \& Sons, New York, 679-720.

[115] Airapetianz, E.S. and Konstantinov, A.I. (1970) Echolocation in Nature. Nauka, Leningrad. (In Russian)

[116] Airapetianz, E.S. and Konstantinov, A.I. (1974) Echolocation in Nature. An English Translation of the National Technical Information Service, Springfield, VA, Joint Publications Research Service, 63328-1.

[117] Suga, N. and O'Neill, W.E. (1980) Auditory Processing of Echoes: Representation of Acoustic Information from the Environment in the Bat Cerebral Cortex. In: Busnel, R.G. and Fish, J.F., Eds., Animal Sonar Systems, Springer, Boston, MA, 589-611. https://doi.org/10.1007/978-1-4684-7254-7_26

[118] Konstantinov, A.I., Makarov, A.K. and Movchan, E.V. (1988) Sensory System for Echolocation in Horseshoe Bats. Russian Academy of Sciences, Moscow. (In Russian)

[119] Suga, N. and Ma, X. (2003) Multiparametric Corticofugal Modulation and Plasticity in the Auditory System. Nature Reviews Neuroscience, 4, 783-794.

https://doi.org/10.1038/nrn1222 
[120] Nikitenko, M.F. (1969) The Evolution and the Brain. Minsk. (In Russian)

[121] Suga, N. and Manabe, T. (1982) Neural Basis of Amplitude-Spectrum Representation in Auditory Cortex of the Mustached Bat. Journal of Neurophysiology, 47, 225-255. https://doi.org/10.1152/jn.1982.47.2.225

[122] Suga, N. (1984) The Extent to Which Biosonar Information Is Represented in the Bat Auditory Cortex. In: Edelman, G.M., Gall, W.E. and Cowan, W.M., Eds., Dynamic Aspects of Neocortical Function, John Wiley \& Sons, New York, 315-373.

[123] Fitzpatrick, D.C., Kanwal, J.S., Butman, J.A. and Suga, N. (1993) Combination-Sensitive Neurons in the Primary Auditory Cortex of the Mustached Bat. Journal of Neuroscience, 13, 931-940. https://doi.org/10.1523/JNEUROSCI.13-03-00931.1993

[124] Fitzpatrick, D.C., Olsen, J.F. and Suga, N. (1998) Connections among Functional Areas in the Mustached Bat Auditory Cortex. Journal of Comparative Neurology, 391, 366-396.

[125] Ma, X. and Suga, N. (2007) Multiparametric Corticofugal Modulation of Collicular Duration-Tuned Neurons: Modulation in the Amplitude Domain. Journal of Neurophysiology, 97, 3722-3730. https://doi.org/10.1152/jn.01268.2006

[126] Ma, X. and Suga, N. (2009) Specific and Nonspecific Plasticity of the Primary Auditory Cortex Elicited by Thalamic Auditory Neurons. Journal of Neuroscience, 29, 4888-4896. https://doi.org/10.1523/JNEUROSCI.0167-09.2009

[127] Kraus, N. and Disterhoft, J.F. (1982) Response Plasticity of Single Neurons in Rabbit Auditory Association Cortex during Tone-Signalled Learning. Brain Research, 246, 205-215. https://doi.org/10.1016/0006-8993(82)91168-4

[128] McMullen, N.T. and Glaser, E.M. (1982) Tonotopic Organization of Rabbit Auditory Cortex. Experimental Neurology, 75, 208-220.

https://doi.org/10.1016/0014-4886(82)90019-X

[129] Imig, T.J., Ruggero, M.A., Kitzes, L.M., Javel, E. and Brugge, J.F. (1977) Organization of Auditory Cortex in the Owl Monkey (Aotus trivirgatus). Journal of Comparative Neurology, 171, 111-128. https://doi.org/10.1002/cne.901710108

[130] Morel, A. and Kaas, J.H. (1992) Subdivisions and Connections of Auditory Cortex in Owl Monkeys. Journal of Comparative Neurology, 318, 27-63. https://doi.org/10.1002/cne.903180104

[131] De La Mothe, L.A., Blumell, S., Kajikawa, Y. and Hackett, T.A. (2006) Thalamic Connections of the Auditory Cortex in Marmoset Monkeys: Core and Medial Belt Regions. Journal of Comparative Neurology, 496, 72-96. https://doi.org/10.1002/cne.20924

[132] Bendor, D. and Wang, X. (2008) Neural Response Properties of Primary, Rostral, and Rostrotemporal Core Fields in the Auditory Cortex of Marmoset Monkeys. Journal of Neurophysiology, 100, 888-906. https://doi.org/10.1152/jn.00884.2007

[133] De la Mothe, L.A., Blumell, S., Kajikawa, Y. and Hackett, T.A. (2012) Thalamic Connections of Auditory Cortex in Marmoset Monkeys: Lateral Belt and Parabelt Regions. The Anatomical Record, 295, 822-836. https://doi.org/10.1002/ar.22454

[134] Rajan, R., Dubaj, V., Reser, D.H. and Rosa, M.G. (2013) Auditory Cortex of the Marmoset Monkey-Complex Responses to Tones and Vocalizations under Opiate Anaesthesia in Core and Belt Areas. European Journal of Neuroscience, 37, 924-941. https://doi.org/10.1111/ejn.12092

[135] Merzenich, M.M. and Brugge, J.F. (1973) Representation of the Cochlear Partition on the Superior Temporal Plane of the Macaque Monkey. Brain Research, 50, 
275-296. https://doi.org/10.1016/0006-8993(73)90731-2

[136] Morel, A., Garraghty, P.E. and Kaas, J.H. (1993) Tonotopic Organization, Architectonic Fields, and Connections of Auditory Cortex in Macaque Monkeys. Journal of Comparative Neurology, 335, 437-459. https://doi.org/10.1002/cne.903350312

[137] Kosaki, H., Hashikawa, T., He, J. and Jones, E.G. (1997) Tonotopic Organization of Auditory Cortical Fields Delineated by Parvalbumin Immunoreactivity in Macaque Monkeys. Journal of Comparative Neurology, 386, 304-316.

https://doi.org/10.1002/(SICI)1096-9861(19970922)386:2<304::AID-CNE10>3.0.CO $\underline{; 2-\mathrm{K}}$

[138] Romanski, L.M., Tian, B., Fritz, J., Mishkin, M., Goldman-Rakic, P.S. and Rauschecker, J.P. (1999) Dual Streams of Auditory Afferents Target Multiple Domains in the Primate Prefrontal Cortex. Nature Neuroscience, 2, 1131-1136.

https://doi.org/10.1038/16056

[139] Kaas, J.H. and Hackett, T.A. (2000) Subdivisions of Auditory Cortex and Processing Streams in Primates. Proceedings of the National Academy of Sciences of the United States of America, 97, 11793-11799. https://doi.org/10.1073/pnas.97.22.11793

[140] Hackett, T.A., Preuss, T.M. and Kaas, J.H. (2001) Architectonic Identification of the Core Region in Auditory Cortex of Macaques, Chimpanzees, and Humans. Journal of Comparative Neurology, 441, 197-222. https://doi.org/10.1002/cne.1407

[141] Tian, B., Reser, D., Durham, A., Kustov, A. and Rauschecker, J.P. (2001) Functional Specialization in Rhesus Monkey Auditory Cortex. Science, 292, 290-293. https://doi.org/10.1126/science.1058911

[142] Petrides, M. and Pandya, D.N. (2002) Comparative Cytoarchitectonic Analysis of the Human and the Macaque Ventrolateral Prefrontal Cortex and Corticocortical Connection Patterns in the Monkey. European Journal of Neuroscience, 16, 291-310. https://doi.org/10.1046/j.1460-9568.2001.02090.x

[143] Remedios, R., Logothetis, N.K. and Kayser, C. (2009) An Auditory Region in the Primate Insular Cortex Responding Preferentially to Vocal Communication Sounds. Journal of Neuroscience, 29, 1034-1045. https://doi.org/10.1523/JNEUROSCI.4089-08.2009

[144] Recanzone, G.H., Engle, J.R. and Juarez-Salinas, D.L. (2011) Spatial and Temporal Processing of Single Auditory Cortical Neurons and Populations of Neurons in the Macaque Monkey. Hearing Research, 271, 115-122. https://doi.org/10.1016/j.heares.2010.03.084

[145] Tian, B., Kuśmierek, P. and Rauschecker, J.P. (2013) Analogues of Simple and Complex Cells in Rhesus Monkey Auditory Cortex. Proceedings of the National Academy of Sciences of the United States of America, 110, 7892-7897. https://doi.org/10.1073/pnas.1221062110

[146] Hackett, T.A. (2008) Anatomical Organization of the Auditory Cortex. Journal of the American Academy of Audiology, 19, 774-779.

https://doi.org/10.3766/jaaa.19.10.5

[147] Hackett, T.A. (2015) Chap. 2. Anatomic Organization of the Auditory Cortex. In: Handbook of Clinical Neurology, Vol. 129, Elsevier, Amsterdam, 27-53.

[148] Brugge, J.F. (1982) Auditory Cortical Areas in Primates. In: Woolsey, C.N., Ed., Cortical Sensory Organization, Vol. 3, Humana Press, New York, 59-70. https://doi.org/10.1007/978-1-4612-5817-9_3

[149] Conley, M., Kupersmith, A.C. and Diamond, I.T. (1991) The Organization of Pro- 
jections from Subdivisions of the Auditory Cortex and Thalamus to the Auditory Sector of the Thalamic Reticular Nucleus in Galago. European Journal of Neuroscience, 3, 1089-1103. https://doi.org/10.1111/j.1460-9568.1991.tb00044.x

[150] Preuss, T.M. and Goldman-Rakic, P.S. (1991) Architectonics of the Parietal and Temporal Association Cortex in the Strepsirhine Primate Galago Compared to the Anthropoid Primate Macaca. Journal of Comparative Neurology, 310, 475-506. https://doi.org/10.1002/cne.903100403

[151] Miller, D.J., Lackey, E.P., Hackett, T.A. and Kaas, J.H. (2013) Development of Myelination and Cholinergic Innervation in the Central Auditory System of a Prosimian Primate (Otolemur garnetti). Journal of Comparative Neurology, 521, 3804-3816. https://doi.org/10.1002/cne.23379

[152] Aitkin, L.M., Kudo, M. and Irvine, D.R.F. (1988) Connections of the Primary Auditory Cortex in the Common Marmoset, Callithrix jacchus jacchus. Journal of Comparative Neurology, 269, 235-248. https://doi.org/10.1002/cne.902690208

[153] Luethke, L.E., Krubitzer, L.A. and Kaas, J.H. (1989) Connections of Primary Auditory Cortex in the New World Monkey, Saguinus. Journal of Comparative Neurology, 285, 487-513. https://doi.org/10.1002/cne.902850406

[154] Hackett, T.A., Stepniewska, I. and Kaas, J.H. (1998) Subdivisions of Auditory Cortex and Ipsilateral Cortical Connections of the Parabelt Auditory Cortex in Macaque Monkeys. Journal of Comparative Neurology, 394, 475-495. https://doi.org/10.1002/(SICI)1096-9861(19980518)394:4<475::AID-CNE6>3.0.CO; $\underline{2-Z}$

[155] Diamond, I.T., Jones, E.G. and Powell, T.P.S. (1968) The Association Connections of the Auditory Cortex of the Cat. Brain Research, 11, 560-579. https://doi.org/10.1016/0006-8993(68)90146-7

[156] Diamond, I.T., Jones, E.G. and Powell, T.P.S. (1969) The Projection of the Auditory Cortex upon the Diencephalon and Brain Stem of the Cat. Brain Research, 15, 305-340. https://doi.org/10.1016/0006-8993(69)90160-7

[157] Pandya, D.N., Hallett, M. and Mukherjee, S.K. (1969) Intra- and Interhemispheric Connections of the Neocortical Auditory System in the Rhesus Monkey. Brain Research, 14, 49-65. https://doi.org/10.1016/0006-8993(69)90030-4

[158] Heath, C.J. and Jones, E.G. (1971) An Experimental Study of Ascending Connections from the Posterior Group of Thalamic Nuclei in the Cat. Journal of Comparative Neurology, 141, 397-426. https://doi.org/10.1002/cne.901410402

[159] Kawamura, K. (1973) Corticocortical Fiber Connections of the Cat Cerebrum. I. The Temporal Region. Brain Research, 51, 1-21. https://doi.org/10.1016/0006-8993(73)90362-4

[160] Pandya, D.N. and Sanides, F. (1973) Architectonic Parcellation of the Temporal Operculum in Rhesus Monkey and Its Projection Pattern. Zeitschrift für Anatomie und Entwicklungsgeschichte, 139, 127-161. https://doi.org/10.1007/BF00523634

[161] Sousa-Pinto, A. (1973) Cortical Projections of the Medial Geniculate Body in the Cat. Advances in Anatomy, Embryology and Cell Biology, 48, 1-42.

[162] Paula-Barbosa, M.M., Feyo, P.B. and Sousa-Pinto, A. (1975) The Association Connexions of the Suprasylvian Fringe (SF) and Other Areas of the Cat Auditory Cortex. Experimental Brain Research, 23, 535-554. https://doi.org/10.1007/BF00234921

[163] Niimi, K. and Matsuoka, M. (1979) Thalamocortical Organization of the Auditory System in the Cat Studied by Retrograde Axonal Transport of Horseradish Peroxidase. Advances in Anatomy, Embryology and Cell Biology, 57, 1-56. 
[164] Andersen, R.A., Knight, P.L. and Merzenich, M.M. (1980) The Thalamocortical and Corticothalamic Connections of AI, AII, and the Anterior Auditory Field (AAF) in the Cat: Evidence for Two Largely Segregated Systems of Connections. Journal of Comparative Neurology, 194, 663-701. https://doi.org/10.1002/cne.901940312

[165] Merzenich, M.M., Colwell, S.A. and Andersen, R.A. (1982) Auditory Forebrain Organization: Thalamocortical and Corticothalamic Connections in the Cat. In: Woolsey, C.N., Ed., Cortical Sensory Organization, Humana Press, Clifton, NJ, 43-57. https://doi.org/10.1007/978-1-4612-5817-9_2

[166] Morel, A. and Imig, T.J. (1987) Thalamic Projections to Fields A, AI, P, and VP in the Cat Auditory Cortex. Journal of Comparative Neurology, 265, 119-144. https://doi.org/10.1002/cne.902650109

[167] Tian, B. and Rauschecker, J.P. (1993) Neuronal Responses to Frequency Modulated Sounds in the Posterior Auditory Field (PAF) of the Cat's Cortex. Society for Neuroscience Abstracts, 19, 843.

[168] Velenovsky, D.S., Cetas, J.S., Price, R.O., Sinex, D.G. and McMullen, N.T. (2003) Functional Subregions in Primary Auditory Cortex Defined by Thalamocortical Terminal Arbors: An Electrophysiological and Anterograde Labeling Study. Journal of Neuroscience, 23, 308-316. https://doi.org/10.1523/JNEUROSCI.23-01-00308.2003

[169] Feliciano, M. and Potashner, S.J. (1995) Evidence for a Glutamatergic Pathway from the Guinea Pig Auditory Cortex to the Inferior Colliculus. Journal of Neurochemistry, 65, 1348-1357. https://doi.org/10.1046/j.1471-4159.1995.65031348.x

[170] Bajo, V.M. and Moore, D.R. (2005) Descending Projections from the Auditory Cortex to the Inferior Colliculus in the Gerbil, Meriones unguiculatus. Journal of Comparative Neurology, 486, 101-116. https://doi.org/10.1002/cne.20542

[171] Lim, H.H. and Anderson, D.J. (2007) Antidromic Activation Reveals Tonotopically Organized Projections from Primary Auditory Cortex to the Central Nucleus of the Inferior Colliculus in Guinea Pig. Journal of Neurophysiology, 97, 1413-1427. https://doi.org/10.1152/jn.00384.2006

[172] Suga, N. (2008) Role of Corticofugal Feedback in Hearing. Journal of Comparative Physiology A, 194, 169-183. https://doi.org/10.1007/s00359-007-0274-2

[173] Schofield, B.R. (2009) Projections to the Inferior Colliculus from Layer VI Cells of Auditory Cortex. Neuroscience, 159, 246-258. https://doi.org/10.1016/j.neuroscience.2008.11.013

[174] Reale, R.A. and Imig, T.J. (1983) Auditory Cortical Field Projections to the Basal Ganglia of the Cat. Neuroscience, 8, 67-86.

https://doi.org/10.1016/0306-4522(83)90026-X

[175] Shmigidina, G.N. (1993) Direct Connections of the Auditory and Limbic Cortex in Rats. Journal of Evolutionary Biochemistry and Physiology, 29, 358-363.

[176] Imig, T.J. and Brugge, J.F. (1978) Sources and Terminations of Callosal Axons Related to Binaural and Frequency Maps in Primary Auditory Cortex of the Cat. Journal of Comparative Neurology, 182, 637-660. https://doi.org/10.1002/cne.901820406

[177] Imig, T.J. and Reale, R.A. (1981) Ipsilateral Cortico-Cortical Projections Related to Binaural Columns in Cat Primary Auditory Cortex. Journal of Comparative Neurology, 203, 1-14. https://doi.org/10.1002/cne.902030102

[178] Read, H.L., Winer, J.A. and Schreiner, C.E. (2001) Modular Organization of Intrinsic Connections Associated with Spectral Tuning in Cat Auditory Cortex. Proceedings of the National Academy of Sciences of the United States of America, 98, 
8042-8047. https://doi.org/10.1073/pnas.131591898

[179] Imaizumi, K., Lee, C.C., Linden, J.F., Winer, J.A. and Schreiner, C.E. (2005) The Anterior Field of Auditory Cortex: Neurophysiological and Neuroanatomical Organization. In: König, R., Heil, P., Budinger, E. and Scheich, H., Eds., Auditory Cortex. A Synthesis of Human and Animal Research, Lawrence Erlbaum Associates Inc., Mahwah-London, 95-110.

[180] Imig, T.J. and Morel, A. (1985) Tonotopic Organization in Ventral Nucleus of Medial Geniculate Body in the Cat. Journal of Neurophysiology, 53, 309-340. https://doi.org/10.1152/jn.1985.53.1.309

[181] Imaizumi, K., Priebe, N.J., Crum, P.A., Bedenbaugh, P.H., Cheung, S.W. and Schreiner, C.E. (2004) Modular Functional Organization of Cat Anterior Auditory Field. Journal of Neurophysiology, 92, 444-457. https://doi.org/10.1152/jn.01173.2003

[182] Guo, W., Chambers, A.R., Darrow, K.N., Hancock, K. E., Shinn-Cunningham, B.G. and Polley, D.B. (2012) Robustness of Cortical Topography across Fields, Laminae, Anesthetic States, and Neurophysiological Signal Types. Journal of Neuroscience, 32, 9159-9172. https://doi.org/10.1523/JNEUROSCI.0065-12.2012

[183] Horie, M., Tsukano, H., Hishida, R., Takebayashi, H. and Shibuki, K. (2013) Dual Compartments of the Ventral Division of the Medial Geniculate Body Projecting to the Core Region of the Auditory Cortex in C57BL/6 Mice. Neuroscience Research, 76, 207-212. https://doi.org/10.1016/j.neures.2013.05.004

[184] Lee, C.C. and Winer, J.A. (2008) Connections of Cat Auditory Cortex: III. Corticocortical System. Journal of Comparative Neurology, 507, 1920-1943. https://doi.org/10.1002/cne.21613

[185] Lindquist, D.H., Jarrard, L.E. and Brown, T.H. (2004) Perirhinal Cortex Supports Delay Fear Conditioning to Rat Ultrasonic Social Signals. Journal of Neuroscience, 24, 3610-3617. https://doi.org/10.1523/JNEUROSCI.4839-03.2004

[186] Downman, C.B., Woolsey, C.N. and Lende, R.A. (1960) Auditory Areas I, II and Ep: Cochlear Representation, Afferent Paths and Interconnections. Bulletin of the Johns Hopkins Hospital, 106, 127-142.

[187] Glaser, E.M., Van der Loos, H. and Gissler, M. (1979) Tangential Orientation and Spatial Order in Dendrites of Cat Auditory Cortex: A Computer Microscope Study of Golgi-Impregnated Material. Experimental Brain Research, 36, 411-431. https://doi.org/10.1007/BF00238513

[188] Beneyto, M. and Prieto, J.J. (2001) Connections of the Auditory Cortex with the Claustrum and the Endopiriform Nucleus in the Cat. Brain Research Bulletin, 54, 485-498.

[189] von Economo, C. and Koskinas, G.N. (1929) The Cytoarchitectonics of the Human Cerebral Cortex. Oxford University Press, London.

[190] Lorente de Nó, R. (1938) Architectonics and Structure of the Cerebral Cortex. In: Fulton, J.F., Ed., Physiology of the Nervous System, Oxford University Press, New York, 291-330.

[191] Merzenich, M.M., Knight, P.L. and Roth, G.L. (1975) Representation of the Cochlea within Primary Auditory Cortex in the Cat. Journal of Neurophysiology, 38, 231-249. https://doi.org/10.1152/jn.1975.38.2.231

[192] Imig, T.J. and Adrian, H.O. (1977) Binaural Columns in the Primary (AI) of Cat Auditory Cortex. Brain Research, 138, 241-257. https://doi.org/10.1016/0006-8993(77)90743-0 
[193] Fitzpatrick, K.A. and Imig, T.J. (1978) Projections of Auditory Cortex upon the Thalamus and Midbrain in the Owl Monkey. Journal of Comparative Neurology, 177, 537-555. https://doi.org/10.1002/cne.901770402

[194] Feliciano, M., Saldana, E. and Mugnaini, E. (1995) Direct Projections from the Rat Primary Auditory Neocortex to Nucleus Sagulum, Paralemniscal Regions, Superior Olivary Complex and Cochlear Nuclei. Auditory Neuroscience, 1, 287-308.

[195] Winer, J.A. and Prieto, J.J. (2001) Layer V in Cat Primary Auditory Cortex (AI): Cellular Architecture and Identification of Projection Neurons. Journal of Comparative Neurology, 434, 379-412. https://doi.org/10.1002/cne.1183

[196] Merzenich, M.M. and Reid, M.D. (1974) Representation of the Cochlea within the Inferior Colliculus of the Cat. Brain Research, 77, 397-415. https://doi.org/10.1016/0006-8993(74)90630-1

[197] Paloff, A. and Hinova-Palova, D. (1998) Topographical Distribution of NADPH-Diaphorase Positive Neurons in the Cat's Inferior Colliculus. The Journal für Hirnforschung, 39, 231-243.

[198] Popelár, J., Nwabueze-Ogbo, F.C. and Syka, J. (2003) Changes in Neuronal Activity of the Inferior Colliculus in Rat after Temporal Inactivation of the Auditory Cortex. Physiological Research, 52, 615-628.

[199] Sugimoto, S., Sakurada, M., Horikawa, J. and Taniguchi, I. (1997) The Columnar and Layer-Specific Response Properties of Neurons in the Primary Auditory Cortex of Mongolian gerbils. Hearing Research, 112, 175-185. https://doi.org/10.1016/S0378-5955(97)00119-6

[200] Yan, J., Zhang, Y. and Ehret, G. (2005) Corticofugal Shaping of Frequency Tuning Curves in the Central Nucleus of the Inferior Colliculus of Mice. Journal of Neurophysiology, 93, 71-83. https://doi.org/10.1152/jn.00348.2004

[201] Tang, J. and Suga, N. (2008) Modulation of Auditory Processing by Cortico-Cortical Feed-Forward and Feedback Projections. Proceedings of the National Academy of Sciences, 105, 7600-7605.

[202] Fitzpatrick, K.A., Imig, T.J. and Reale, R.A. (1977) Thalamic Projections to the Posterior Auditory Field in the Cat. Society for Neuroscience Abstracts, 3, 6-7.

[203] Morel, A. and Imig, T.J. (1984) Neurons in the Tonotopic Thalamus of the Cat Are Topographically Organized with Respect to Their Target Fields in Auditory Cortex. Society for Neuroscience Abstracts, 10, 244-245. 


\section{List of abbreviations}

A, AAF-anterior auditory field

A1, AI-primary auditory field

A2, AII-secondary auditory field

A3, AIII-tertiary auditory field (in the dog)

AC-auditory cortex

$\mathrm{ADF}$ - anterior dorsal auditory field (in the ferret)

AES-anterior ectosylvian field (in the dog)

AV-anterior-ventral auditory field (in the gerbil)

AVF-anterior ventral auditory field (in the ferret)

BDA-biotinylated dextran amine

CF-CF-CF-CF combination sensitive area (in bats)

$\mathrm{Cg}$-cingular cortex

$\mathrm{CP}$ - caudal parabelt (in primates)

CTB-fluor-conjugated cholera toxin B subunit

$\mathrm{D}$-dorsal auditory field (in the gerbil)

DA-dorsoanterior field (in the mouse)

DC-dorsocaudal field (in guinea pig)

DCB - secondary dorsocaudal field (in guinea pig)

$\mathrm{DM}$-dorsomedial field (in the mouse)

$\mathrm{DP}$-dorsoposterior field

$\mathrm{DRB}$ - secondary dorsal-rostral (in guinea pig)

DSCF-doppler-shifted CF processing area (in bats)

DZ-dorsal auditory zone

$\mathrm{EP}$ - posterior ectosylvian field (in the cat)

$\mathrm{EPD}$-dorsal part of posterior ectosylvian field (in the cat)

EPM-medial part of posterior ectosylvian field (in the cat)

EPV - ventral part of posterior ectosylvian field (in the cat)

FM-FM-frequency modulations combination sensitive area (in bats)

$\mathrm{HF}$-high-frequency area (in bats)

ICC-central nucleus of inferior colliculus

Ins-insular cortex

$\mathrm{M}$-medial MGB

MEG-medial ectosylvian gyrus (in the ferret)

MES-medial ectosylvian field (in the dog)

MGB-medial geniculate body

P, PAF-posterior auditory field

PES- posterior ectosylvian field (in the dog)

$\mathrm{PPF}$ - posterior pseudosylvian field (in the ferret)

$\mathrm{PRh}$ - perirhinal cortex

PSF-posterior suprasylvian field (in the ferret)

$\mathrm{PV}$ - parietal-ventral cortical area (in the hedgehog)

$\mathrm{R}$-rostral field 
$\mathrm{RP}$ - rostral parabelt (in primates)

$\mathrm{RT}$-rostrotemporal field (in primates)

$\mathrm{S}$-small core auditory field (in guinea pig)

S2-secondary somatosensory cortical area (in the hedgehog)

$\mathrm{SF}$-suprasylvian peripheral field (in the cat)

SRAF - suprarhinal auditory field (in the rat)

STG-superior temporal gyrus (in primates)

$\mathrm{Te}$-temporal auditory field (in the cat)

UF-ultrasound field (in the mouse)

UR-unspecific region (in the rat)

V-ventral MGB

$\mathrm{VCB}$ - secondary ventrocaudal field (in guinea pig)

$\mathrm{Ve}-$ ventral auditory field (in the cat)

VP-ventroposterior auditory field

VRB - secondary ventral-rostral field (in guinea pig) 